Portland State University

PDXScholar

1992

\title{
A Qualitative Case Study of Chinese Teaching Assistants' Communication in the U.S. University Classroom
}

Lina Lu

Portland State University

Follow this and additional works at: https://pdxscholar.library.pdx.edu/open_access_etds

Part of the Education Commons, and the International and Intercultural Communication Commons Let us know how access to this document benefits you.

\section{Recommended Citation}

Lu, Lina, "A Qualitative Case Study of Chinese Teaching Assistants' Communication in the U.S. University Classroom" (1992). Dissertations and Theses. Paper 4379.

https://doi.org/10.15760/etd.6263

This Thesis is brought to you for free and open access. It has been accepted for inclusion in Dissertations and Theses by an authorized administrator of PDXScholar. Please contact us if we can make this document more accessible: pdxscholar@pdx.edu. 
AN ABSTRACT OF THE THESIS OF Lina Lu for the Master of Arts in Speech Communication presented May 13, 1992.

Title: A Qualitative Case Study of Chinese Teaching Assistants' Communication in the U.S. University Classroom.

APPROVED BY THE MEMBERS OF THE THESIS COMMITTEE:
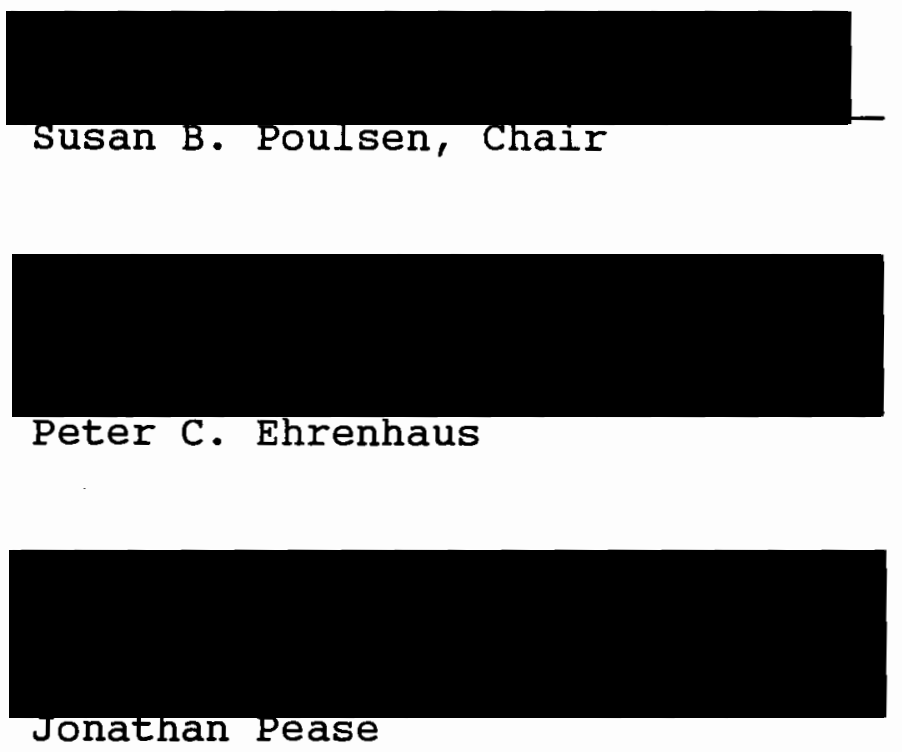

This is an exploratory, interpretive study, focusing on classroom communication experiences of Chinese teaching assistants (CTA) in a U.S. university. The research asked: What are CTAs' experiences communicating in the U.S. university classroom? How do they interpret their 
experiences from their own perspective? And what is their emergent adaptation pattern to the U.S. university classroom?

A phenomenological perspective was used as the organizing, theoretical framework for the study. Relevant literature on international teaching assistants (ITA) was reviewed as well as intercultural communication based on attribution theory and general cross-cultural adaptation. Open-ended, in-depth taped interviews and classroom observations were conducted with 17 CTAs who were employed in a U.S. university during the 1990-1991 academic year.

Using techniques of interpretive analysis, Chinese TAs' descriptions of their experiences communicating with students in the U.S. university classroom and their interpretations of these experiences were analyzed and categorized. The categories coalesced around the following topic areas: perception of classroom teaching in the U. S. university, identification of communication problems, CTAs' problem-solving strategies, and attitudes toward the TA position.

Based on analyses of emergent themes derived from data, this study reveals that CTAs' classroom behavior and communication is influenced by their cultural background and that their expectations of the university classroom setting and U.S. students' academic levels do not fit the 
U.S. higher educational system and affect their classroom communication with students.

The Chinese TAs use three specific strategies to adapt to the U.S. classroom: imitating, preparing and adopting, however, few of them understand underlying values of the U.S. classroom culture. Thus, ITA training programs would be helpful for CTAs' adaptation. Based on CTAs' experiences, this study suggests that both pre-term and long term training programs would meet CTAs' needs and that such content as American English, knowing how to be a U.S. teacher and understanding the U.S. university classroom culture would strengthen ITA training programs.

Finally, in view of the study's limitations, the thesis concludes with suggestions for future research. 
A QUALITATIVE CASE STUDY OF CHINESE TEACHING ASSISTANTS' COMMUNICATION IN THE U.S. UNIVERSITY CLASSROOM

\author{
by
}

LINA LU

A thesis submitted in partial fulfillment of the requirements for the degree of

\author{
MASTER OF ARTS \\ in \\ SPEECH COMMUNICATION
}

Portland State University

1992 
TO THE OFFICE OF GRADUATE STUDIES:

The members of the Committee approve the thesis of Lina Lu presented May 13, 1992.
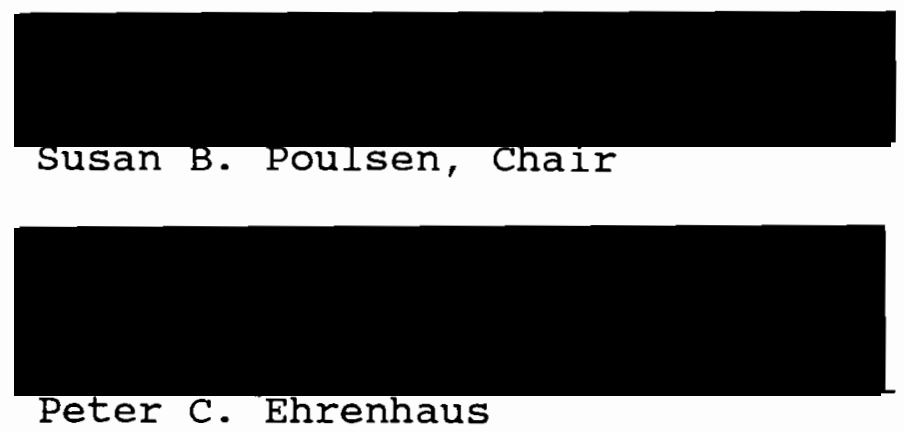

APPROVED :

Jonathan Pease

Stephen A. Kosokoff, Chair

Department of Speech Communication

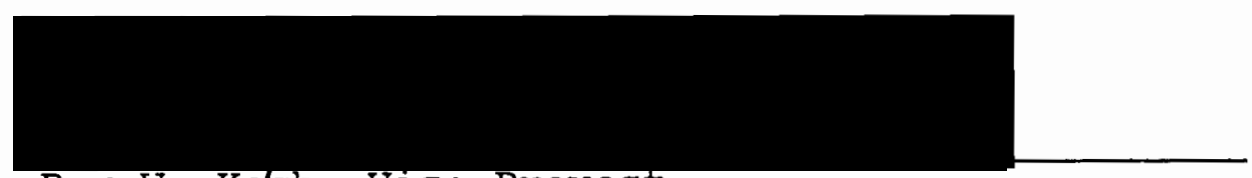

Roy W. Koch, Vice Provost

for Graduate Studies and Research 
To The Memory of My Father

\section{LU TIEFU}

$$
\text { (1924-1976) }
$$




\section{ACKNOWLEDGEMENTS}

I am very grateful to $\mathrm{Dr}$. Charlie white, who has made my graduate studies in the United States possible and greatly supported me throughout my studies.

My special thanks to my chair of the thesis committee, Dr. Susan Poulsen, for her encouragement and guidance at the every step of the design and the writing of the thesis, and for her patience in helping me edit and polish the work.

Other members of the thesis committee, Dr. Peter Ehrenhaus and Dr. Jonathan Pease, merit special thanks for their valuable suggestions, especially Dr. Ehrenhaus's suggestions on literature review and methodology, which greatly improved the quality of the thesis.

I would like to express my sincere thanks to all Chinese teaching assistants at Portland State University for their participation and support.

I am always grateful to my mother, my husband and my son, for their love, encouragement and patience for years. My sincere thanks also go to my two younger brothers, who took care of my son during my studies in the United States. Thank You All. 
TABLE OF CONTENTS

PAGE

ACKNOWLEDGEMENTS........................

LIST OF TABLES......................... viii

LIST OF FIGURES....................... ix

CHAPTER

I INTRODUCTION..................... I

International Teaching Assistants in

the U.S. Universities ........... 1

Purpose of the study................ 3

My Background as an Investigator........ 3

Chinese students in the U.S...........4

Research Questions................ 5

The Framework of the study...........6

II RELATED LITERATURE $\ldots \ldots \ldots \ldots \ldots \ldots \ldots \ldots$

Studies of International Teaching

Assistants in the U.S. Universities... 8

Areas of the Studies on ITAs

ITA Training Programs

Summary: ITA Issues

Attribution Theory and Intercultural

Communication............ 21

Attribution Theory

Intercultural Communication Based in Attribution Theory

High- and Low-Context Cultures and Attribution Theory

Cultural characteristics: China and the U.S. 
Cross-Cultural Adaptation .......... 28

General Issues of Cultural Adaptation Situational Adaptation

Phenomenology and Social Interpretation... 31

Two Views Affecting Thinking About Communication

Phenomenology

Schutz' Social Phenomenology

III RESEARCH METHODS AND DATA COLLECTION

PROCEDURES................... 38

Introduction $\ldots \ldots \ldots \ldots \ldots \ldots \ldots \ldots$

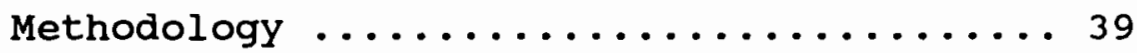

Qualitative Methods

Research Design ................41

Sampling Procedures

Data Gathering Instruments

Pilot study

Data Collection ...............48

Individual Interviews

Classroom observations

Data Analysis ................ 53

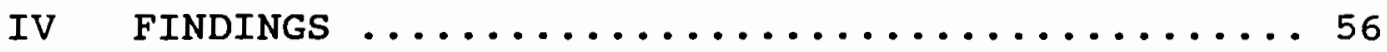

Sample Demographic Characteristics ..... 56

CTAs' Background

Current CTA Experience

Perception of classroom Teaching in a U.S. University.........6 60

Perceptions of U.S. Professors

Perceptions of U.S. Students

Perceptions of the Relationships

Summary

Between CTAs and students

Identification of Communication Problems.. 75 
Communication Problems

Internal Attributions

External Attributions

Summary

CTAs' Problem-Solving strategies .......8 83

Working with Other TAs

Preparing Before Teaching

Use of Non-verbal Behavior

Teaching Method Adaptation

Efforts Toward Becoming Familiar

Summary

With U.S. Students

Attitudes Toward the TA Position .......993

Getting Teaching Experience

Improving One's English

Learning Through Teaching

Understanding U.S. Students

Making Friends

summary $\ldots \ldots \ldots \ldots \ldots \ldots \ldots \ldots \ldots$

Endnote $\ldots \ldots \ldots \ldots \ldots \ldots \ldots \ldots$

V DISCUSSION AND CONCLUSION ............ 100

CTAS' Classroom Communication

in a U.S. University......... 100

Language

Cultural Expectations of Classroom

Setting

Cultural Expectations of students'

Mathematical Capabilities

CTAS' Adaptation to the U.S. University

classroom............... 113

CTAs' Adaptation Strategies

Two Levels of Adjustment

Implications For ITA Training Programs... 117

Training Program Type

Training Program Content

Limitations of the study .......... 122

Future Research ................ 124 
Conclusion ................. 126

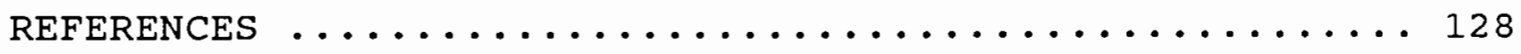
APPENDICES

A INFORMED CONSENT ................. 135

B CHINESE TEACHING ASSISTANT DEMOGRAPHIC

INFORMATION $\ldots \ldots \ldots \ldots \ldots \ldots \ldots \ldots \ldots \ldots \ldots$

C observation gUide ................... 137

D INTERVIEW GUIDE ................... 138 


\section{LIST OF TABLES}

I Population of PSU's ITAs and CTAs by Department.. 42

II PSU's CTÁs by Department .................. 43

III CTAs' Length of Time in the U.S. ........... 58

VI CTA Demographic Feature by Department ........ 59 


\section{LIST OF FIGURES}

FIGURES

PAGE

1. Robert Kaplan: Patterns of Cultural Logic...... 11

2. Shaw \& Garate's Three Unbalanced Equations Between ITAs and U.S. Students.......... 14 
CHAPTER I

\section{INTRODUCTION}

\section{INTERNATIONAL TEACHING ASSISTANTS \\ IN THE U.S. UNIVERSITIES}

The number of international students in U.S. institutions of higher education has been increasing rapidly in recent decades. The Institute of International Education reported that by 1990 one out of every four graduate students attending U.S. universities was from outside the country (Open Doors, 1990). Many U.S. universities with graduate programs employ international teaching assistants (ITA) to teach undergraduate courses, especially in the natural sciences, engineering, business, mathematics, and computer science (Byrd, Constantindes \& Pennington, 1989). However, because they speak English as a second language and are relatively unfamiliar with U.S. culture and undergraduates, they may encounter difficulties in the classroom.

In recent years, international teaching assistants (ITA) have come under close scrutiny across the nation and complaints about ITAs by students have generated investigations and initiatives at all levels, from individual departments to state legislatures ( Bailey, Pialorsi \& Faust, 1984; Chism \& Warner, 1987; Nyquist, 
Abbott \& Wulff, 1989; Constantinides, 1987a; BuerkelRothfuss \& Gray, 1990; Byrd, Constantinides \& Pennington, 1989). This concern has been referred to as the "foreign TA problem" (Bailey, 1984). Among others, Bailey (1984) described the problem as:

... international students... who have - to varying degrees - less than perfect control of English, the medium of instruction. Furthermore, these non-native speaking (NNS) TAs may lack a clear understanding of their roles within the American educational system. Thus, both linguistic and cultural difficulties contribute to the difficulties faced by foreign TAs. Consequently, the interaction between non-native speaking teaching assistants and their students is complicated and sometimes problematic. The communication difficulties engendered by this situation are collectively labeled the "foreign TA problem". (p.3)

Many U.S. universities employing ITAs have conducted research and set up ITA training programs to help ITAs to adapt to teaching in the U.S. university classroom. However, much of the research on ITA issues and most training programs have addressed the concerns of U.S. undergraduates being taught by ITAs while the concerns of ITAs, especially their own experiences, have received little attention (Saal, 1987). The current study was conducted to address the limited information available on the ITAs' perspective of their own classroom experiences. 
PURPOSE OF THE STUDY

The purpose of this study was to explore the classroom experiences of Chinese teaching assistants (CTA) in a U.S. university and how they interpret their own experiences. In other words, the focus of the study was on understanding CTAs' experiences from their perspective. The following questions were addressed in the study. What are CTAs' experiences of communicating with their students in the U.S. university classroom? What are CTAs' interpretations of their communication experiences in the U.S. university classroom? What are emergent patterns of CTAs' adjustment to communication in the U.S. university classroom? These questions can be best explained from phenomenological perspective. This study will use phenomenology as a framework to interpret CTAs' experiences. The general assumptions which underlie phenomenological inquiry are developed in chapter II.

\section{MY BACKGROUND AS AN INVESTIGATOR}

In the past six years, I have been teaching in various U.S. universities and colleges, public and private, in the northwest area. In the first term, I was surprised and overwhelmed by U.S. students' "strange" behaviors in the classroom and they did not seem satisfied with my "god-like" lectures. Gradually, I realized that the classroom 
communication between teachers and students in the U.S. university is different from that in China. My experience of teaching in U.S. universities indicated that instructors from outside the U.S. culture had to undergo an adjustment process before being effective in the U.S. university classroom. I wondered if this was only my personal experience, or did every Chinese instructor have similar experiences? What did other chinese teaching staff experience in U.S. universities? How different is classroom communication in the U.S. from that in China? How do Chinese instructors adapt to U.S. classroom communication? This study was sparked by my interest in these questions. I chose Chinese teaching assistants (CTA) in a U.S. university as a case study to examine these questions.

\section{CHINESE STUDENTS IN THE U.S.}

Students from the People's Republic of China first entered U.S. universities in 1975. According to the 19891990 edition of Open Doors, during the past ten years, Chinese students have been the fastest growing group of international students in the United States. In 1985, students from China totaled 10,100, making China eleventh among foreign countries sending students to the U.S. BY 1990 the number had jumped to 33,390 , constituting the largest group among international students. Of these 33,390 Chinese students, nearly $30 \%$ are admitted to graduate 
programs where most of them study applied engineering, computer science, mathematics and natural sciences (Open Doors, 1990).

Thus, Chinese graduate students, as the largest group among international students in the U.S., are frequently teachers for entry-level undergraduate courses. However, there are few studies on Chinese teaching assistants (CTA) in the U.S. university. This leaves unanswered such questions as: What are their experiences of being TAs in U.S. universities? How do they perceive U.S. higher education and U.S. undergraduates? What difficulties do they face in their instruction? What help do they need in order to communicate effectively in the classroom? How do they adapt to U.S. institutions? Literature on general Chinese characteristics seems inadequate, even misleading, for understanding and explaining CTAs' behaviors and attitudes. Some research focusing on CTAs needs to be conducted systematically so as to answer these questions.

\section{RESEARCH QUESTIONS}

The purpose of this study was to describe an area that has received little research focus, that is CTAs' communication experiences with U.S. students in the U.S. university classroom from their own view, and their adaptation to classroom communication. This study took Chinese teaching assistants (CTA) who were employed in a 
U.S. university, as a case to explore the CTAs' perspective of the "foreign TA problem".

The research questions are posed based on the intended focus of this study and the preceding discussion.

1. What are CTAs' experiences of communicating with U.S. students in the U.S. university classroom?

2. What are CTAs' interpretations of their own communication experiences in the U.S. university?

3. What are emergent patterns of CTAs' adjustment to communication in the U.S. university classroom? In the study two terms will be used frequently which can be defined as follows:

1. International teaching assistant (ITA):

A graduate teaching assistant in a U.S. university, whose native language is not English, and whose cultural upbringing occurred outside the U.S. (Lalande \& Strasser, 1987)

2. Chinese teaching assistant (CTA):

A graduate teaching assistant in a U.S. university who is a national of the People's Republic of China and comes to the U.S. with a student visa.

THE FRAMEWORK OF THE STUDY

The thesis is divided into five chapters. Chapter I introduces the ITA issue in U.S. universities and the purpose of the study. Chapter II reviews related 
literature, including studies of ITA issues, attribution theory, cross-cultural adaptation, and phenomenology. Chapter III, Research Method and Data Collection Procedures, describes the qualitative research method, research design, the data gathering instruments, pilot study, and the data collection and analysis procedures. Chapter IV, Findings, classifies the collected data into five categories. Chapter V, Discussion and Conclusions, describes CTAs' communication and adaptation patterns in the U.S. university classroom. Implications and limitations of the study are also discussed. 


\section{RELATED LITERATURE}

The purpose of this study was to describe and analyze the communication experiences of Chinese teaching assistants (CTA) with U.S. students in the U.S. university classroom, understand CTAS' interpretations about their own experiences, and explore emergent patterns of CTAs' adjustment to communication in the U.S. university classroom. The first section of this chapter reviews related studies on international teaching assistants (ITA) as well as related literature on intercultural communication and cross-cultural adaptation. In the second section I discuss in general terms the phenomenological perspective within the social sciences.

STUDIES ON INTERNATIONAL TEACHING ASSISTANTS IN THE U.S. UNIVERSITIES

\section{Areas of the studies on ITAS}

Prior studies and investigations of international teaching assistants (ITA) have focused on three areas: language, pedagogical skills, and cross-cultural understanding.

Language. Since the medium of instruction in U.S. university classrooms is English, the ITAs' use of and 
proficiency in English is always the first thing that students complain about, e.g., "Poor English skills," "heavy accent." Hinofotis and Bailey's studies (1980) on ITAs' English proficiency show that, among other language skills (vocabulary, grammar and flow of speech), pronunciation is the single most important factor in U.S. students' assessment of the ITA's overall ability, and often triggers negative comments from the students (p. 125). In addition, Dunkel \& Rahman's, (1987) and Yule \& Hoffman's, (1990) studies suggest that some ITAs need work on stress and intonation patterns, especially in the terms associated with their discipline. However, Hinofotis and Bailey's (1980) survey of UCLA students enrolled in the classes of ITAs indicate that students who are not majoring in the same fields of study were significantly more critical of the ITAs' use of English than students who share a common academic major with the instructor.

Beyond minimum proficiency, even ITAs with good conversational English may need additional training to learn to use their English effectively in the U.S. undergraduate classroom. Few ITAs will have had sufficient opportunities to practice the public speaking skills that differentiate the spoken English of teaching from the spoken English of conversation (Byrd \& Constaninides, 1988).

Indeed, English proficiency is a factor which cannot be ignored. The National study of Teaching Assistants (Diamond 
\& Gray, 1987), among others, contains a recommendation that international students should be tested for spoken language competency and that those falling below an accepted standard should not be given teaching responsibilities until that standard is met. Many institutions that employ ITAs have used different tests to evaluate ITAs' oral English proficiency before they take on teaching responsibilities (Mellor, 1987; Eck, 1987; Anderson-Hsieh, 1990). However, Gillespie's (1988) study suggest that pre-employment examinations of English proficiency may not be a reliable indicator of prospective ITAs' potential effectiveness as classroom teachers. So far, there is no standard test able to meet all the needs of institutions.

Pedagogical skills. U.S. undergraduates complain that international teaching assistants do not teach in ways with which they are familiar (Constantindes, 1987a). This area concerns the ability to teach in the way that the undergraduates of a given institution expect. Most ITAs' teaching skills, appropriate in their home countries, do not fit the U.S. education system and U.S. student academic level, especially in public universities. The ability to write on the board while speaking to the students, to establish appropriate eye contact, to set a tone in a classroom familiar to the U.S. undergraduate, to respond appropriately to students' interruptions and questions - all of these "contribute to the ITAs' ability to communicate and 
their absences are often more distracting than accent itself" (Constantinides \& Byrd, 1986, p.29).

Lowman (1984) also reports that one of the most prominent factors in student expectations of instructors concerns clarity of presentation, that is "a logically organized way" of presenting material with frequent use of concrete examples. The "logically organized way" expected by American students consists of a linear, deductive pattern. However, this is not the dominant logic pattern of some other cultures. Kaplan (1980) stated that logic evolves out of a culture, and it is not universal. He described logical organization patterns of different cultures by analyzing paragraph development in writings of students from different cultures (see Figure 1).

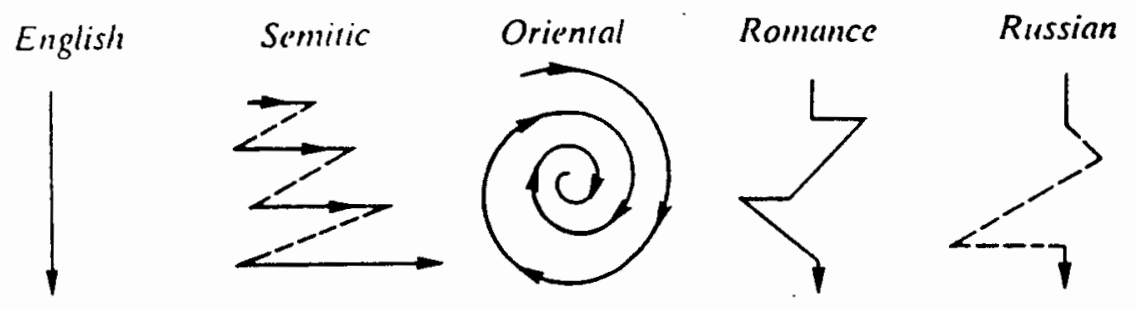

Figure 1. Robert Kaplan: Patterns of Cultural Logic.

Kaplan explained that the thought patterns which speakers of English appear to expect as an internal part of their communication is a sequence that is dominantly linear in its development. However, in the Arabic language (for all Semitic languages), paragraph development is based on a 
complex series of parallel constructions, both positive and negative. Unlike English or Semitic languages, Oriental writings are marked by what may be called an approach by indirection. The circles turn around the subject, but the subject is never looked at directly. Things are developed in terms of what they are not, rather than in terms of what they are. For example, Kaplan explains, an English expository paragraph usually begins with a topic statement, and then, by a series of subdivisions of that topic statement while compositions written by oriental speakers are developed in terms of what they are not, rather than in terms of what they are. The following is an example of such writings.

Definition of College Education

College is an institution of an higher learning that gives degrees. All of us needed culture and education in life, if no education to us, we should to go living hell.

One of the greatest causes that while other animals have remained as they first man along has made such progress is has learned about civilization.

The improvement of the highest civilization is in order to education up-to-date.

So college education is very important thing which we don't need mention about it.

Instead of beginning with a topic statement, the composition talks about subject-related things until the last paragraph where it presents a conclusion which is in fact partially a 
topic statement and partially a statement that the whole basic concept of the assignment is so obvious that it does not need discussion. The paper arrives where it should have started by English composition standards.

In analyzing writings of French and Spanish students, Kaplan found that much greater freedom to digress or to introduce extraneous material is available in French or in Spanish, than in English. In Russian writings, sentences are irrelevant to the central idea of the paragraph in the sense that they are parenthetical amplification of structurally related subordinate elements. Particularly relevant to this study is the contrast between the linear pattern of logic prominent in U.S. culture and the dominant circular organizational pattern that typifies China (Oriental), the cultural background of the participants in this study.

Reid's findings (1987) of cultural differences in learning/teaching styles support Kaplan's idea that different cultures have their own dominant patterns of information-presenting and reasoning. Her research on cultural differences in learning/teaching styles indicates for example, that members of industrialized societies and members of nonindustrial societies respond to visual illusions quite differently. In many cases, neither students nor ITAs are aware that difficulty in learning/teaching in the classroom, high frustration levels, 
and even failure may not rest solely in ITAs' "poor English", but rather, may be related to a teaching method that reflects the teacher's rather than students' cultural logical system.

\section{Cross-Cultural Understanding of Classroom}

Communication. This is an area of increasing concern to scholars in ITA research field. Based on their studies, Shaw and Garate (1984) suggest that three unbalanced equations occur between ITAs and U.S. students in their classroom communication (see Figure 2).

\section{ITAS}

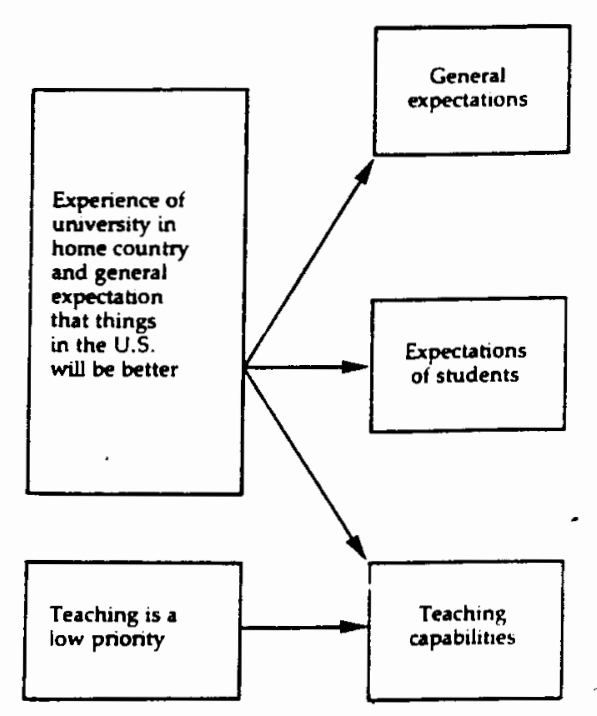

U.S. Students

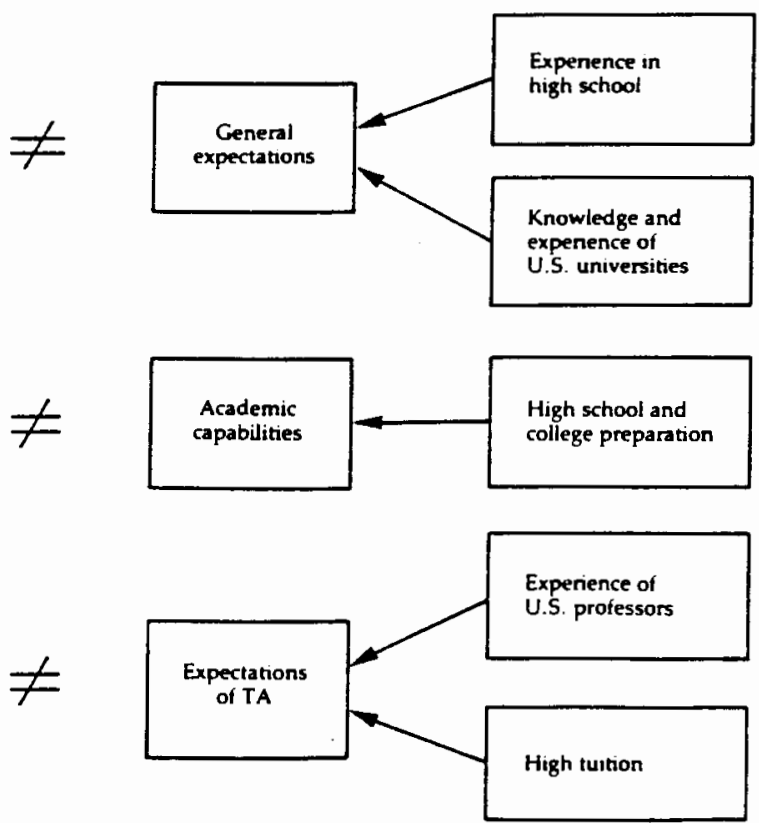

Figure 2. Shaw \& Garate's Three Unbalanced Equations Between ITAs and U.S. Students. 
As Shaw \& Garate explain, in general ITAs' expectations of what happens in a university classroom do not match those of students. In particular, what ITAs think they can expect from students do not match students' capabilities and, likewise, what students expect from ITAs does not match ITAS' capabilities.

These unbalanced equations result from differences in educational background, and educational philosophy and purposes. Constantinides Byrd's findings (1986) suggest that one of the factors which reduces the ITAs' ability to communicate effectively in the U.S. university classroom is the ITAS' educational background. Their research shows that a majority of the ITAs completed their undergraduate study outside the U.S. in educational systems that are different from the American educational system. For example, Chinese teaching assistants (CTA) come from a secondary educational system in which they had to pass examinations before they were admitted to an undergraduate program. Thus, CTAs' undergraduate experience is in marked contrast to the situation in many U.S. universities, especially the universities with an open-door policy. Deegan and Tillery (1985) describe the open-door policy as open access which "seek, recruit, enroll and retain every possible student ( $p$. 19). They go further: "Thus, the doors were open not just to colleges as opportunities for achievement but also to courses and programs for which students might not yet be 
qualified" (p. 19). In such open-door universities, ITAs encounter an unfamiliar situation. Constantinides \& Byrd (1986) state:

In open-door universities (and sometimes others as well) many students take algebra, trigonometry, chemistry, and physics for the first time. The foreign TA, who had developed a much higher level of mathematics and science proficiency than that to enter a university in his/her country, can find it difficult to adjust to teaching at a "remedial" level (p. 29).

Differences in educational philosophy and purposes are another barrier to ITAS' effective communication with U.S. students. The United States educational system pays at least lip service to the idea that "the role of education is to help its people become better citizens by teaching them to question, to think, to develop problem-solving techniques" (Constantinides \& Byrd, 1986, p. 29). In contrast, Chinese TAs for example, were educated in an educational system in which a premium is placed on memorization, passing on known truths and facts from one generation to another, the antithesis of problem-solving and exploration (Hsu, 1981). Constantinides \& Byrd's findings (1986) indicates that when ITAs employ their own educational background to teach, U.S. students find the teaching approach unfamiliar, uncomfortable, and unhelpful. The ITA, in some cases, finds U.S. students rude and disruptive because they have the "nerve" to interrupt and ask probing questions rather than passively accepting the information 
given them. The negative evaluations between ITAs and U.S. students based on the differences in educational philosophy have "a lot of influence on the ITAs" attitude toward the American students", which, in turn, influences their communication effectiveness (Costantino, 1985, p. 4). Many researchers (Sadow \& Maxwell, 1982; Bernhardt, 1977; Pica, Barnes \& Finger, 1990; Shaw \& Garate, 1984; Ronkowski, 1987; Saal, 1987; Costantino, 1987; Byrd \& Constantinides, 1988 ; Byrd, Constantinides \& Pennington, 1989) point out that not only is it important for ITAs to recognize differences in education systems and the classroom behaviors resulting from them, but they must also handle general cultural differences. The American quality of individualism and its attendant competitiveness and aggressiveness may be difficult for ITAs to cope with if they come from cultures where the emphasis is on cooperation more than competition, on respect for elders more than egalitarianism, on establishments and institutions more than individual initiative, and on collective rather than individual goals. Thus, it is important for ITAs to have a firm grounding in cross-cultural awareness and understanding of how the U.S. undergraduates think, feel and behave.

\section{ITA Training Programs}

Over the past several years, considerable progress has been achieved in conceptualizing and implementing comprehensive programs to prepare ITAs for teaching (Abraham 
\& Plakans, 1988; Chase, 1970; Bailey, Pialorsi \& Faust, 1984; Chism \& Warner, 1987; David, 1987; Sarkisian, 1985; Sequeira \& Costantino, 1989 and stato-spicer \& Nyquist, 1979). Most emphasize the importance of addressing the three areas mentioned in the preceding paragraphs ( $\mathrm{pp}$. 8-17). The overall objective of ITA training programs is to increase the ITAs' communication effectiveness, and the specialized context for which the training is provided in the U.S. university classroom (Costantino, 1985). Specifically, ITA training programs are designed to increase ITAs' speaking competence, listening comprehension, ability to organize teaching materials, classroom management, presentation skills, and knowledge of U.S. cultural traits. Types of Training Programs. International teaching assistants (ITA) training programs have multiplied and vary from institution to institution according to the needs of ITAs and the institution. Among others, Constantinides (1989) developed a typology of training programs that categorizes programs by the length of the program with its timing. (1) The first type is the orientation program that lasts from one to five days before the beginning of an academic term. Such a program focuses on providing ITAs with information about the U.S. postsecondary educational system, the institutions in which the ITAs will teach, and specific requirements of departments. (2) The second type is a pre-session program that lasts from one to four weeks 
before the start of an academic term and provides opportunities for addressing the cross-cultural, pedagogical, and language needs of ITAs. ITAs attending the program are able to not only receive information about the U.S. educational system, philosophy, and purpose but also to practice applying that information. They can change their teaching and language behaviors before they begin teaching for the first time and perhaps avoid making a bad impression. (3) The third type consists of a concurrentterm program occurring during the first term (ten to fifteen weeks) that the ITA teaches. This training program provides more time for the exploration of such issues as appropriate teaching behaviors. It includes the chance to observe the teaching situations in which ITAs must function. (4) The program that involves the largest investment in time is a pre-term program that lasts from ten to fifteen weeks and occurs during the term before the ITA interacts with undergraduates. This training program offers more time for ITAs to assimilate information about the U.S. educational system, and the specific institution and its students, as well as to practice the institutional skills and language needed for success.

Areas of Focus of ITA Training Programs. Most training programs that equally emphasize three skill areas language, pedagogy, and cross-cultural communication maintain the perspective that "communication competence" 
(Kim, 1988) is the ultimate goal, because ITAs need to learn not only appropriate language but also appropriate behaviors for specific contexts (Sequeria \& Costantino, 1990). The language component includes listening comprehension as well as accent reduction and use of appropriate structures and vocabulary. The pedagogical skill component includes an explanation of the U.S. educational philosophy and system, and some teaching techniques. The cross-cultural communication skill aspect refers to skills connected with serving in a teaching capacity, which would include not only classroom communication but also such communication as holding office hours and dealing with student complaints (Constantinides, 1987b).

\section{Summary: ITA Issues}

The preceding review of studies on ITAs and on the training programs has provided an outline of research that has been done in this area. Some research focuses on ITA issues in general (Byrd \& Constantinides, 1986; Yule \& Hoffman, 1990); some focuses on ITAs in a university (Hinofotis \& Bailey, 1980; Costantino, 1985; Rounds, 1987; Sequeira \& Costantino, 1990; and Smith, 1987); still other material focuses on a discipline (Gillespie, 1988; \& Buerkel-Rothfuss \& Gray, 1990). However, these are not concerns of this study. The present research suggests that classroom interactions are related to cultural values and norms, that differing implicit norms can cause communication 
problems, and that careful study of the classroom context can help to reveal these underlying patterns. The concern of this study is to concentrate on TAs from a single culture with different discipline backgrounds and to explore their experiences of classroom communication in the U.S. university. Previous studies of ITA difficulties, and training programs as presently developed, do not explicitly address the ITA's perspective of their own university classroom experiences. The present research takes Chinese TAs employed in a U.S. university as a case and specifically focuses on the ITAs' description of their own experiences.

The following section will review related literature on intercultural communication between U.S. and China, and on cross-cultural adaptation of Chinese students to the U.S. university.

ATTRIBUTION THEORY AND INTERCULTURAL COMMUNICATION

\section{Attribution Theory}

Attribution theory is concerned with understanding the manner in which people organize and assign meaning to the events and actions they experience and observe. According to Heider (1958), attribution concerns the entire stream of information processing that underlies the organization of social behavior, from social perception through the causal analysis of phenomenal perceptions. 
Kelley (1972) contributes three basic assumptions related to causal attribution. (1) People attempt to determine the causes of behavior and when in doubt, they look for information that will help answer the question; people assign causes systematically, that is, they examine the convariation between a given effect and various possible causes; and (3) the attributed cause affects the perceiver's own feelings and behavior.

Communicator attributions determine in large part their meaning for given situations. Attribution processes organize the information into meaningful units that provide the basis for social inference and social action. Attributions one makes offer coherence for the self. However, person A may attribute meaning based on $\mathbf{x}$ set of attributions while co-communicator, person B, has achieved internal coherence based on $y$ set of attributions. Thus, achieving internal coherence does not automatically insure that interpersonal coherence follows. According to Ehrenhaus (1983), interpersonal coherence results if each attributor structures "the continuous stream of communication similarly, and cue structures of expectation congruently" (p. 261), however, if communicators make different attributions about the identical situation, interpersonal coherence may be "achieved and lost repeatedly throughout an interaction, although the linguistic 
contributions of the communicators may be smoothly coordinated" (Ehrenhaus, 1983, p. 261).

Intercultural communication Based in Attribution Theory

How do people from different cultures make attributions about each other's behaviors in their interactions? The question involves both the study of attribution processes and the study of intercultural communication. In the attribution process, people use their structures of expectations to make attributions of their own and others' behaviors, and these structures are based upon their experiences of the world within a culture.

Ehrenhaus (1983), Detweiler (1978), Duncan (1976) and Brislin (1981) discuss the influence of culture on expectation structure and attribution. First, Ehrenhaus (1983) discusses how culturally structured expectations influence attribution process. He views culture as a series of structured expectations which guide and enable fluid social interaction, and as a collection of expectations by which we construct, test, and modify our interpretations of discourse and of other's purposes as inferred through discourse. He goes on:

Culture does not impose a cognitive map upon persons, but provides them with a set of principles for map-making and navigation.... (culture) direct our attention to stable cognitive structures... (and) our attention toward cognitive processing" (1983, p. 263). Detweiler's (1978) research indicates that the 
attribution process is dependent upon the category width of the attributor. The observer with broad categories may have multiple interpretations of one behavior; by contrast, the observer with narrow categories may accept discrepant interpretations of one behavior. The former is likely to be less sure about his attributions while the latter seems to be more certain of his attributions. Further, Detweiler systematically investigates the relationship among culture, category width, and attributions, and concludes that culture influences the attributor's category width, which in turn influences attributions. He found that the attribution process is influenced by whether an observer judges an actor as culturally similar or dissimilar. When narrow categorizers and broad categorizers judge the same action, the former makes stronger judgements about culturally dissimilar actors than the latter. The cultural dimension is central to this attribution effect.

Duncan's (1976) attribution study finds that whites attribute negative acts to personal traits when the actor is black and to situational factors when the actor is white. Duncan's study indicates that for cross-group interactions, negative acts are attributed to actor's dispositions, while positive acts are attributed either to situational factors or to exceptional characteristics that distinguish the person from his group. 
Brislin (1981) also recognizes the importance of attribution processes in intercultural communication. He asserts that attributors are much more likely to be influenced by the negativity effect given perceived culturai dissimilarity, and that negative information about dissimilarity is considerably more influential than positive information in drawing conclusions about dissimilar' intentions and causal dispositions:

Attribution theory has only recently been applied to intercultural communication contexts, therefore, there has been little research conducted, especially research on cross-cultural communication between Americans and Chinese speakers. This study, based on the findings of attribution research previously mentioned, will try to use attribution theory to explain communication experiences of Chinese TAs in the U.S. university classroom.

High- and Low-context Cultures and Attribution Theory

Hall (1976) defines a high-context culture (HCC) as one in which "people are deeply involved with each other... information is widely shared" and "simple messages with deep meaning flow freely" (p. 91). He describes a lowcontext culture (LCC) as "highly individualized", "somewhat alienated", with "relatively little involvement with people" (p.91). Further, Hall points out that the meaning of a high-context message is embedded in the physical context, i.e., internalized within the person's knowledge of 
contextual factors which affect interpersonal interaction. A low-context message on the other hand, relies almost completely on the explicit code. Hall's concept of high-and low-context cultures is very useful for explaining crosscultural interaction with attribution theory.

Ehrenhaus (1983) describes the relationship between attribution processes and high- and low-context cultures. One of his propositions concerning the mediation of culture on attributions suggests that HCC members tend to be situationally sensitive attributors while LCC members tend to be dispositionally sensitive attributors. He explains:

In HCCs, communicative behavior is proportionally more a product of situational forces than of the internal characteristics of the interactants. Relatively less information needs to be explicitly encoded.... In LCCs,... Iimited contextual information requires messages to be high in information value. Communication is presumed to reflect more the character of the interactants than the character of the situation, since constraints upon their behavior are fewer than in HCCs (pp. 263-264).

According to Hall, China is at the high-context end of the scale and U.S. culture is at the low-context end. Since these two cultures are at the opposite ends, how do chinese (HCC) make attributions of their and Americans' behaviors in their communication? How do Americans (LCC) do this? The following section will briefly review these two distinctive cultures. 
Cultural Characteristics: China and the U.S.

Several studies have pointed out notable differences between China (HCC) and the U.S. (LCC). In one such study, Alxander, Cronen, Kang, Tsou, and Banks (1986), comparing Chinese and American students in relationship development, find that the chinese subjects believe they can infer an individual's intellectual potential by knowing his socialrelated information. This finding supports Gudykunst's (1983) conclusion that in HCCs, cultural or social background is considered salient for learning about others and being able to predict the persons' behavior, whereas in LCCs, personal information is considered salient. This seems to fit Hall's description of members of HCCs having more awareness of the filter the culture provides.

Another distinction between high-context and lowcontext cultures is that "people are deeply involved with each other in HCCs while people are "highly individualized" in LCCs (Hall, 1976, p. 91). Stewart (1972) contrasts Chinese and Americans in their social and personal relationships. He describes U.S. culture as follows:

The Americans stress on the individual as a concrete point of reference begins at a very early age when the American child is encouraged to be autonomous. The self-centeredness of the child is seldom questioned. It is implicitly accepted that each child or person should be encouraged to decide for himself, develop his own opinions, solve his own problems, have his own things and, in general, learn to view the world from the point of view of the self. (p. 68) 
On the other hand, in Chinese culture dependence is highly valued.

And among the Chinese, dependence on others is desirable for it strengthens the relationship among people. Chinese parents, for instance, take pride in being dependent on their children and supported by them in a manner to which they are not unaccustomed. (Stewart, 1972, p. 72)

The studies cited above focus on but a few of the areas where Chinese and Americans cultural differences have been noted.

\section{CROSS-CULTURAL ADAPTATION}

General Issues of Cultural Adaptation

International teaching assistants (ITA), like any international students coming to study at an American university, must undergo a process of cross-cultural adaptation in order to be effective in the U.S. classroom. Kim (1988) is one of several researchers who defines crosscultural adaptation:

...cross-cultural adaptation refers to the process of change over time that takes place within individuals who have completed their primary socialization process in one culture and then come into continuous, prolonged first-hand contact with a new and unfamiliar culture. (p.38)

According to $\mathrm{Kim}$, cross-cultural adaptation is not a smooth, linear process, rather, it is "stress-adaptationgrowth dynamics of intercultural communication experiences" 
(p. 54). When experiencing a new culture, a person has to go through many stressful emotional "lows", which are viewed as "the internal resistance of the human organism against its own cultural evolution" (Kim, 1988, p. 55). As the person faces the demands of the host environment and copes with the accompanying stress, parts of his internal organization undergo small changes. The interior organization of the person is in flux as he continues to communicate with and adapt to the host environment. stress, then, is responsible not only for suffering, frustration, and anxiety, but also for providing the impetus for adaptive personal transformation and growth - the learning and creative responses to manage new cultural circumstances. "Stress, adaptation, and growth, together, define the internal dynamics of a person's cross-cultural experiences in a 'draw-back-to leap' pattern similar to the movement of a wheel" (Kim, 1988, p. 56).

Many attempts have been made to identify factors that contribute to cross-cultural adaptation, such as traits, personality, motivation and pluralistic societies. However, this research will consider situation as an adaptation factor since the focus of this study is on the U.S. university classroom settings rather than on general social settings. 


\section{Situational Adaptation}

Theoretical perspectives on situational adaptation relevant to this study are offered by Detweiler, Brislin and Mccormack (1983). They suggest a situational factor which may contribute to cross-cultural adaptation. They assert:

... an understanding of situational influences is absolutely essential for interculturalist: intercultural situations are characterized not by changes in the personality of the person but by change in the situation. (p. 104)

This situation strategy, which is based on the belief that situations predict behavior, focuses on general dimensions of situational differences. An individual learns about a culture's food, personal speaking distances, modes of responding to friends or authority figures, male-female responses, and the like. Many of these are actually situational influences on the individual. The authors' suggestion is that an adequate understanding of how situations vary has tremendous promise for improving intercultural adjustment, as it has for other aspects of social behavior.

In the adjustment to U.S. culture, all Chinese teaching assistants (CTA) are faced with a new cultural situation: the U.S. university classroom. In order to adjust to this new situation, they have to understand it. For example, an understanding of behavioral norms within the U.S. classroom is vital. CTAs need an awareness of the social rules by which U.S. students and their instructors operate: the 
amount of one-to-one interaction between students and instructor, the correction or disagreement mechanisms employed by the instructor, the instructor's body language, demeanor, techniques for beginning and ending classes, and how U.S. students negotiate classroom procedures with instructors (Bernhardt, 1977; Jordan, 1982).

How do Chinese TAs adapt to the U.S. university classroom? What are their experiences of adaptation? What difficulties do they have to face? How do they deal with these difficulties? These questions can most productively be approached from the perspective of Chinese TAs employed in the U.S. universities. However, few researchers have studied and given attention to the experiences of this particular population. Therefore, there is a need for investigation that explores Chinese TAs' subjective experiences. The present study addresses this need.

\section{PHENOMENOLOGY AND SOCIAL INTERPRETATION}

Two Views Affecting Thinking About Communication

The ways in which communication scholars conduct inquiry and construct theories depends largely on their epistemological assumptions. Basically these assumptions can be divided into two broad opposing views. Drawing on Littlejohn's (1989) discussion, the first view, world view I, treats reality as distinct from the human being. It assumes a physical reality that is self-evident to the 
observer. Objectivity is all important and investigators are required to define the exact operations to be used in observing events. In contrast, World View II, the second perspective, takes a different turn by viewing reality in process. In this view Littlejohn states:

people take an active role in creating knowledge. A world of things exists outside the person, but the individual can conceptualize these things in a variety of useful ways. Knowledge therefore arises not out of discovery but from interaction between knower and known. For this reason perceptual and interpretive processes of individuals are important objects for study. (pp. 25-26)

According to Littlejohn, communication research in World view I is characterized by behavioristic methods, aiming to make laws and universal statements and developing generalization that hold true across situations and over time, and viewing the human being as a reactive object. In contrast, qualities characterizing communication studies in World View II include active interpretations of human being's social behaviors by researchers, emphasis on the individual subjective response, social knowledge through symbolic interactions, and meaning of communication constructed in processes.

As mentioned earlier, the research inquiry of this study is to explore Chinese TAs' communication experiences in the U.S. university classroom and interpret their experiences. Therefore, taking a World View II position is 
appropriate to this study. Human beings experience the world meaningfully and intentionally, and their experience reveals their perception of the world. These assumptions are explained by phenomenological and social interpretive perspectives.

\section{Phenomenology}

Littlejohn (1989) defines phenomenology as "the study of the ways in which human beings experience the world" ( $p$. 135), the world from the perspective of the perceiver, the individual who experiences the world. Littlejohn states that phenomenology makes actual lived experience the basic data of knowledge, in other words, phenomenology means letting things become manifest as what they are, without forcing our own categories on them.

The phenomenologist is committed to understanding social phenomena from the actor's own perspective. He or she examines how the world is experienced. The important reality is what people perceive it to be. (Taylor and Bogdan, 1984, p. 2)

Phenomenology involves the idea that human behavior is a meaningful process of living a situation (Pilotta, 1983). According pilotta, human behavior is primarily the experience of meaning, hence, it is experience and meaning attributed to it by the experiencer that provides the integrative elements for the study of humans. Thus, experience itself is interpretative-integrative. 
For purposes of this study, Schutz's social phenomenology is an appropriate framework within which situate the study of ITAs' classroom experiences. It provides an explanatory frame for understanding how experience is meaningfully interpreted from the perspective of the Chinese TAs themselves.

\section{Schutz's Social Phenomenology}

Schutz (1967) applied phenomenology to social life and investigated social events such as communication from the perspective of those actually participating in it. He stated that phenomenology is concerned with that "cognitive reality which is embodied in the processes of subjective human experiences" (1970, p. 56). According to Schutz (1967), all direct experiences of humans are experiences in, and of their "life-world."

They constitute it, they are oriented toward it, they are tested in it. The life-world, simply, is the whole sphere of everyday experiences, orientations, and actions through which individuals pursue their interests and affairs by manipulating objects, dealing with people, conceiving plans, and carrying them out (p. 57).

For Schutz (1967), individuals define for themselves the reality of the world they encounter in the "natural attitude." People are all born and raised separately, assimilating the values of their own surroundings. Accordingly, depending on the particular motives, beliefs, desires, aspirations, etc., they have learned, they will 
experience the world differently and act in the world from a different point of view. Thus, subjectively, no two persons could possibly experience the same situation in the same way. Most of all, each has entered this present situation with his own purposes and objectives in mind, and appraises it accordingly; and these purposes and the concomitant appraisals are rooted in his past, in his unique life history.

Schutz (1970) dealt with the means by which an individual orients himself in life situations, his "store of experience" and his "stock of knowledge on hand." The individual interprets his experiences and observations, defines the situation in which he finds himself, and makes any plans for even the next minutes by consulting his own knowledge base. This knowledge constitutes the unique pattern by which people assimilate new events and experiences in an orderly, systematic way.

According to Schutz (1967), the world is organized by rules of typicality, that is, principles found in people's unquestioned past experiences allow them to anticipate the meaning they will experience in their perceptions of familiar objects, things, and people. Social knowledge consists of formules, or social recipes. These are typical, well-understood ways of doing things. They "enable people to group things according to some kind of mutually understood logic, to solve problems, to take roles, to 
communicate, and to establish proper behavior in different situations" (1967, p. 163). What Schutz discusses about formules or social recipes may be considered as a means to interpret Chinese TAS' communication experiences in the U.S. university classroom. since CTAs in this study experienced their undergraduate studies in china, their formules or social recipes of university classroom behaviors and communication patterns are structured and based on their past experiences in China. Their expectations of students and academic abilities, their own way to conduct classroom teaching, their interpretations of both students' and their own behaviors and their predictions of classroom situations are all guided by formules structured by their culture. Do CTAS' formules of classroom communication work when they teach in the U.S. university classroom? What are their experiences teaching in the U.S. university? How do they interpret their experiences? These are inquiries of this study and can be usefully explained by Schutz' social phenomenological perspective.

In sum, reality, for phenomenologists, does not exist in some abstract realm awaiting discovery by inquiring observers. It is, rather, embedded in perceptions of the world each individual experiences, the result, not of passive discovery, but of an active, disciplined process of subjective constitution. People are unique in alone constituting real objects and events, and giving meaning to 
the world. Thus, phenomenology offers an appropriate framework within which to examine the Chinese TAs' perceptions of their experiences in the U.S. classroom. The next chapter describes research methods used in the study and date collection procedures. 


\section{CHAPTER III}

RESEARCH METHODS AND DATA COLLECTION PROCEDURES

\section{INTRODUCTION}

The purpose of this study was to explore the classroom experiences of Chinese teaching assistants in a U.S. university and how they interpret those experiences. The focus of the study was on understanding Chinese TAs' experiences from their perspective. The following questions were addressed: What are CTAS' experiences of communicating with their students in the U.S. university classroom? How do CTAs interpret those communication experiences? What are emergent patterns of CTAs' adjustment to communication in the U.S. university classroom?

This chapter is divided into three sections. Section I discusses the qualitative research methods used in this study while section II describes the research design, including sampling procedures, data gathering instruments (observation and interview), and the pilot study. Section III provides an overview of the data collection procedures. 


\section{METHODOLOGY}

\section{Qualitative Methods}

A qualitative research approach was employed to conduct this study. Taylor and Bogdan (1984) list ten characteristics of qualitative research: 1. It is inductive. 2. the researcher "looks at settings and people holistically; people, settings, or groups are not reduced to variables, but are viewed as a whole" (p. 5). 3 . Researchers are "sensitive to their effects on the people they study" (p. 5). 4. Researchers try to understand people from their own frame of reference. 5. Researchers suspend their own "beliefs, perspectives and predispositions" ( $p$. 5). 6. All perspectives are valuable. 7. It is humanistic. 8. Researchers emphasize validity in their research. 9 . Researchers believe that "all settings and people are worthy of study" (p. 8). 10. Qualitative research is a craft.

This method was selected as an appropriate one for the following reasons. First, the purpose of this study was not to test existing theory; rather, utilizing sensitizing concepts to guide the research (Blumer, 1979), the purpose was to discover how Chinese teaching assistants (CTAs) interpret their own experience of communicating with U.S. students in a U.S. university classroom; how they adapt to the culture of the U.S. university education system, and to generate conclusions from these data. In other words, the goal of this study was to gain access to the respondents' 
categories and assumptions by which they (CTAs) construct a concept of communicating in a U.S. university classroom. It was the native person's categories and assumptions, not their quantitative occurrence that was under investigation. While quantitative methods have been usefully employed in the study of international teaching assistants, this study was differently designed. This research did not attempt to produce the phenomena of interest, nor to control for the effects of various factors. This study focused on the chinese teaching assistants'(CTA) perspective of their experience, a feature that has received little research attention. Further, the phenomenological perspective taken in this study calls for a general research design and specific data gathering methods (pp. 44-45) that facilitate assessing and examining the participants' own perspective of their lived experiences. Thus, precise a priori categories were not available. The categories and assumptions of CTAs' experience and interpretations were defined during the process of research rather than before the study. "The qualitative investigator expects the nature and definition of analytic categories to change in the course of a project" (Mccracken, 1988, p.16). While a quantitative approach calls for use of predetermined, closed measurement, the absence of precise a priori categories in this study indicated the more appropriate use of openly coded categories (Philipsen, 1984). 
The research questions for which data were sought did not allow respondents to respond readily and precisely, therefore, a qualitative approach was indicated. As Mccracken notes:

When the questions for which data are sought are likely to cause the respondent greater difficulty and imprecision, the broader, more flexible net provided by qualitative techniques is appropriate" (McCracken, 1988, p.17).

Finally, the study worked longer, and with greater care, with a few people than more superficially with many of them. As McCracken (1988) notes, "Qualitative research... is much more intensive than extensive in its objectives" ( $\mathrm{p}$. 17) .

In sum, the purpose and goals of this study were most appropriately addressed utilizing the qualitative research methods -- naturalistic inquiry, inductive analysis, holistic perspective, personal contact and insight, context sensitivity, and design flexibility (Patton, 1990, p.41-42).

\section{RESEARCH DESIGN}

\section{Sampling Procedures}

Population. For purposes of this study, the sample was limited to Chinese teaching assistants (СTA). The sample was drawn from the current population of international teaching assistants employed at Portland State University (PSU). According to the Institutional Research and Planning Office of PSU, in the 1990-1991 academic year, PSU had 58 
international teaching assistants (ITA), twenty of whom were from the People's Republic of China. Table I presents the population of PSU's ITAs and CTAs by department.

TABLE I

POPULATION OF PSU'S ITAS AND CTAS BY DEPARTMENT

\begin{tabular}{|c|c|c|c|}
\hline Department & $\begin{array}{l}\text { Total } \\
\text { ITAs* }\end{array}$ & CTAS & $\begin{array}{c}\text { TAs from } \\
\text { other countries }\end{array}$ \\
\hline Music & 1 & 1 & \\
\hline Foreign Lang. & 12 & 1 & 11 \\
\hline Geology & 1 & & 1 \\
\hline Political sci. & 1 & 1 & \\
\hline Biology & 1 & & 1 \\
\hline speech comm. & 1 & $1 * *$ & \\
\hline Mathematics & 6 & 2 & 4 \\
\hline Chemistry & 6 & 2 & 4 \\
\hline Physics & 8 & 6 & 2 \\
\hline Computer Sci. & 1 & & 1 \\
\hline Civil Engi. & 1 & & 1 \\
\hline Mechanicäl Engi. & 5 & & 5 \\
\hline Electr. Engi. & 14 & 6 & 8 \\
\hline Total & 58 & 20 & 38 \\
\hline
\end{tabular}

Sample Type and size. Chinese teaching assistants (CTA) met the following criteria: a) they were teaching at Portland State University (PSU) during the 1990-1991 academic year, b) they were non-native-English speakers, and c) they were nationals of the People's Republic of China. of the twenty CTAs, three were not included in this study. Two CTAs were subjects in the pilot study (see pp. 44-47), and the third was myself as an investigator. The remaining 
seventeen CTAs included in this study represent seven departments. The following table illustrates the CTAs by department.

TABLE II

PSU'S CTAS BY DEPARTMENT

\begin{tabular}{ll}
\hline Department & CTAs \\
\hline & \\
Music & 1 \\
Foreign Lang. & 1 \\
Political Sci. & 1 \\
Mathematics & 2 \\
Chemistry & 2 \\
Physics & 5 \\
Electr. Engi. & 5 \\
\hline
\end{tabular}

Contacting CTAs. Prior to the study, I contacted the Office of Grants and contracts at Portland state University to obtain permission from the Human Subjects Research Review Committee to conduct this research. After official approval was received, I contacted each department secretary to obtain the CTAs' names, addresses, phone numbers, their teaching schedules and classroom numbers. Then, I called each of them to introduce myself and explain my study. When I met them, I again explained the purposes of the study and told them that their participation in this study would greatly be appreciated, that their names would not be cited 
in the study, and that any direct quotes would be coded so as to protect participant confidentiality. They were also told that if they did not feel comfortable, they were free to withdraw at anytime. If they were willing to participate in this study, I made appointments with them for a classroom observation and a personal, face-to-face, interview. All seventeen chinese teaching assistants agreed to participate in the study.

\section{Data Gathering Instruments}

observation guide. The observation guide used in this study was drawn from "The Foreign Teaching Assistants Manual" (Byrd, Constantinides \& Pennington, 1989), and has been developed and tested in several different university ITA training programs: University of Wyoming, University of Hawaii and Georgia State University. It contains observation items of language activities (speaking, reading, writing and listening) and nonverbal acts (movement, gesture, eye contact, facial expressions, and so forth) (See Appendix c). Validity and reliability measures were not available.

Video-taping was planned for each classroom observation in this study. The purpose of video-taping was to provide an opportunity to analyze for specific nonverbal behaviors.

Interview guide. The interview guide employed in this study was developed by myself (see Appendix D). The guide consists of thirteen open-ended questions that were designed 
to elicit information on CTAs' classroom experiences and their interpretations of their experiences. The questions were designed to be general and open-ended in order to encourage subjects to talk about issues that were most important to them. They could also be used as more specific areas of inquiry if the subjects had difficulties answering a general question. Thus the interview guide was treated as a flexible tool of inquiry within which it was possible to rearrange questions to fit the interviewees. The last question provided both the interviewer and interviewees with an additional opportunity if issues of importance to the interviewees arose, if the interviewer wanted to understand the thinking behind a belief or action, or if categories and contexts arose which seemed to be significant to previously collected data.

\section{Pilot study}

Prior to actual data collection, a pilot study was conducted. The purpose of the pilot study was to ascertain the appropriateness of the constructed categories of the two guides and reconstruct them, if necessary, to meet the requirements of this study. Four subjects were involved in the pilot study: two Japanese teaching assistants in the Foreign Languages Department, and two Chinese teaching assistants (CTA), one from Physics Department and the other from Electrical Engineering Department. I made some changes in the observation and interview guides based on suggestions 
from pilot study subjects. A category on paralanguage was added to the observation guide (see Appendix C).

In the interviews with pilot study subjects, questions from the interview guide were answered readily and with much detail by three subjects. One subject did not know how to answer the questions even though she understood them, and suggested that it would probably be better to "let me have a free talk about myself, and if I miss something, then you ask me."

The pilot study was very useful in informing me of several limitations in the interview guide. First, the second question (tell me some of your interesting experiences teaching at Portland state University that you never experienced in China) seemed too broad to begin with. Some subjects did not know where to start and it took them a while to recall their experience. The intention of this question was to relax people by a general question and provide them with an opportunity to talk. However, while some subjects were comfortable starting from a general question, some were not. I discovered that I needed to follow the subjects in the interview, that is, if they liked to begin by answering a general question, the above question could be used; if they could not answer a general question, then specific questions such as questions 3,4 or 6 could be used first. 
Second, some subjects were not comfortable with the structured interview questions because they were not familiar with some terms, like "teaching style", or "classroom behaviors" etc. I frequently rephrased questions in an effort to make them clear to each subject whenever I realized their confusion. Some subjects did not like question-answer interviews, rather, they preferred to have a non-guided conversation. I decided that if a subject seemed uncomfortable with the structured interview questions, I would encourage a less-structured conversation. Within this conversation, I looked for opportunities to probe the subject's experience and interpretation. Lofland and Lofland (1984) point out the importance of flexibility in the interview questions:

... [an interview] guide is not a tightly structured set of questions to be asked verbatim as written, accompanied by an associated range of reworded answers. ... You want interviewees to speak freely in their own terms about a set of concerns you bring to the interaction, plus whatever else they might introduce. (p. 59)

Third, when I checked the adequacy of categories of the interview guide by asking "Is there anything else you would like to say?", all four subjects of the pilot study mentioned their satisfaction with being teaching assistants at Portland State University even if they talked a lot about difficulties they had when they were first-term TAs. They suggested a question on satisfaction be included in the 
interview guide. I agreed with their suggestion, and added a new question to the guide (see Question 13 in Appendix D).

\section{DATA COLLECTION}

\section{Individual Interviews}

Interviews were conducted in the spring term of 1991 at Portland State University (PSU). All seventeen Chinese teaching assistants (CTA) participated in interviews for this study. The length of interviews varied from one to two hours, and the total number of interview hours was twenty seven. All interviews were with a single person except one interview that included two CTAs. Interview times and locations were carefully arranged with informants and proceeded without interruption. Interviews were conducted in offices, empty classrooms, laboratory rooms, apartments, and at the interviewer's home.

At the beginning of the interview, I reviewed that I was a CTA at PSU and this research was for my thesis. I explained that I was particularly interested in CTAs' experiences in the U.S. university. I then explained that I would ask some questions about their experiences as a TA at PSU. After that, I would like them to add anything that they thought to be important but not covered in the interview questions.

Further, I explained that there were no right or wrong answers and that all information given to me was 
confidential. I reminded them that their names, classes taught, or other identifying information would not be included in the study and that these interviews would not affect their TA positions. Also, I encouraged the CTAs to feel free to stop me at any time if they did not understand my questions, if they wanted to return to a previous topic, if they thought a particular topic was important to probe, or for any other reasons.

I requested permission to tape record the interviews as what they told me was important and I did not want to miss or forget anything. Again I indicated that I would be the only person who would listen to the tapes. All interviews were tape recorded except with one CTA, whom I met in the school by accident after having failed many times to contact him. I took this opportunity to conduct an interview with him in an empty classroom. This interview was not recorded because the tape recorder was not available, however, I took extensive interview notes.

I also presented the Informed Consent Form (Appendix A) and asked them to read and sign it. Most of them were not familiar with this form and seemed bewildered by the formality of such a form and did not know what to do. They commented that there was nothing like this in China. I explained that the form was used to protect people who participate in research and has been used over the last several decades in the United States. 
After the CTAs were comfortable with the wording of the Informed consent Form, I began the interviews with demographic questions (see Appendix A). Following this, I proceeded with the rest of the questions.

Sixteen interview tapes were transcribed in the summer of 1991. Each interview tape was listened to from beginning to the end without stopping to understand the general ideas and then transcribed, sentence by sentence. Although it is ideal to transcribe tapes immediately following each interview, it was not possible to do so. Thus, all transcribing was completed after the original four week data collection period. The interview tapes, transcriptions, CTAs' demographic information forms and observation notes were given an identifying number for later analysis.

\section{Classroom observations}

The Chinese teaching assistants at Portland state University can be divided into three groups. One group was categorized as classroom TAs, who conducted lectures, led discussions, prepared tests and evaluated students' achievements. The second group was laboratory TAs, who explained laboratory experiment aims and procedures, assisted students to complete the experiments, answered questions and evaluated the laboratory reports. The third group was categorized as tutoring TAs, who corrected assignments, answered lecture-related questions and assisted individuals in solving problems of their assignments. 
Twelve of the seventeen Chinese teaching assistants (CTA) in the sample were observed during spring term, 1991. of the five CTAs not observed, three CTAs had conducted laboratory instructions at the beginning of the term and had already completed their laboratory instructions by the time actual data collection began. I was unable to contact the other two CTAs until almost the end of the term and by that time they had finished their laboratory instructions or tutoring.

The twelve observations were conducted in regular instruction settings, five of which were classroom teaching observations and seven of which were laboratory observations. Each observation lasted 50 minutes, for a total of 10 hours of field observation. In the first two observations, the CTAs being observed introduced me to their students and reserved a seat for me in front of the classroom. I found that I was considered as an "outsider" and the front-row seat position did not help my observation at all. After that, I told the CTAs not to introduce me and I went to the classroom 10 minutes early so that I could select a back-row seat. During the observations, I wrote observed information categories in the observation guide and took notes for questions to be discussed with the CTAs when interviewing. More detailed data were obtained in classroom teaching observations than in lab observations as more interactions and communication between the CTAs and students 
occurred in the classroom teaching settings than in laboratory settings.

The study called for video-taping each observation. However, when I discussed the possibility of video taping and tried to solicit CTAs' cooperation, only three agreed to be video taped. Although the CTAs agreed, without hesitation, to be observed, they were generally reluctant to be video taped. The major reasons they gave were: 1) they did not feel comfortable to be video-taped and they would be very nervous when teaching, and 2) video-taping might interfere with their instructions: that is, the students might pay attention to video-taping rather than listen to the lectures and they could not conduct instruction in that situation. The three CTAs who agreed to be video-taped requested that $I$ do the video-taping myself rather than having another outside observer in their classroom or laboratory.

I learned to operate the camera and practiced videotaping twice with the video camera prior to observations. Before video-taping, I checked the laboratory rooms, plug locations, experiment desk arrangement and room lights. When video-taping, I did not have an opportunity to take notes, and the observation notes of these three CTAs were recorded when I later viewed the tapes. 
DATA ANALYSIS

Analysis, as a continuous process, occurred throughout data collection. In the whole process of listening to the taped interviews, reading classroom observation notes, transcribing recorded tapes, categorizing data, and grouping data into different categories, analysis occurred with each level based on, but different from the previous one. Lofland and Lofland (1984) discuss data collection and its analysis:

...analysis and data collection run concurrently for most of the time expended on the object, and the final stage of analysis (after data collection has ceased) becomes a period for bringing final order to previously developed ideas. Contrast this with the former situation, wherein the researchers, after data collection has ceased, has to begin to make some kind of coherent sense out of the mass of running descriptions, documents, and so on. Excellent work can, of course, still be produced. We only suggest that it is more difficult to do so. (p. 131)

I read interview transcriptions three to five times for each interview. While reading, I took notes and made comments on the data. Sometimes I had to go back to listen to the tape in order to try and ascertain the respondents' feelings. The process of reading data occurred in two steps. The first step was to read vertically, that is, I read an individual transcription from beginning to end without stopping in order to get the respondent's main ideas. I found that each respondent had his/her own flow of 
describing their experiences. Their main ideas went back and forth throughout an entire transcription. I identified more than ten categories as a result of the vertical reading at all transcripts. These categories were considered as first-level analysis, that is, the focus of this level was to "identify and construct the categories used by subjects to conceptualize their own experiences" (Goetz \& Lecompte, 1980, p. 54 ).

The second step was to read horizontally. In this step, I chose the identical data which I had assigned into the same category from all 17 transcripts. The first purpose of horizontal reading was to compare data to see whether they are common to most respondents or unique to particular respondents. The second purpose of the step was to examine whether a particular category was appropriate. At the end of this step, I reduced data into five typologies. These typologies were considered as secondlevel analysis.

After completing these two steps, I started "drawing back in order to think of the total picture (Lofland \& Lofland, 1984, p. 136). I re-read each single transcription to be sure that no important data were ignored or miscategorized. As I worked with the data, I gained a clearer picture in my mind about categories which remained as important parts of the final analysis. As Taylor and Bogdan (1984) described: 
...by studying themes, constructingg typologies, and relating different pieces of data to each other, the researcher gradually comes up with generalizations. (p. 134)

The following chapter presents the data collected and analyzed in this study. 


\section{CHAPTER IV}

\section{FINDINGS}

The Chinese teaching assistants (CTAs) interviewed for this study were asked to talk about their experiences of being graduate teaching assistants in a U.S. university. Participants' responses to this question are discussed in this chapter. The chapter is divided into five major sections. The first presents CTA demographic characteristics, while the second discusses the CTAs' perception of classroom teaching in the U.S. university. The third section describes communication problems between CTAs and students and internal and external attributions of the problems. The fourth section discusses the problem solving strategies that CTAs employed in their interactions with students. The last section highlights CTAs' attitudes toward the TA position.

\section{SAMPLE DEMOGRAPHIC CHARACTERISTICS}

For purposes of this study, the sample was limited to Chinese graduate teaching assistants. The following demographic features are included: sample size, gender, nationality, length of time teaching in China, length of time learning English in China and TOEFL scores (Test of 
English as a Foreign Language), academic degree already attained and currently sought, length of time in the U.S., department where they work, types of $T A$, and length of time as a TA.

\section{CTAs' Background}

Among the 17 participants, 8 were women and 9 were men. All of them came with a student visa from the People's Republic of China.

Length of Time Teaching in China. Eleven (65\%) of the CTA had teaching experience in China, varying from 1 year to 5 years. Six (35\%) of the CTAs did not have any teaching experiences in China.

Length of Time Learning English in China and TOEFL

Score. All of the CTAs learned English as a second language (ESL) in China before they came to the U.S. The length varied from 1 year to 10 years. Five studied 1 - 3 years; six studied $4-6$ years; and six studied 7 - 9 years. All of them had passed the TOEFL examination before they were offered TA positions (a score of 550 is required by the Graduate school of PSU).

Degree attained and sought. In this sample, $12(70 \%)$ already had their bachelor's degree while 5 (30\%) had their master's degree. Sixteen of the CTAs acquired their academic degrees in the People's Republic of China while one earned a bachelor degree in the U.S. All of the CTAs included in this study were involved in graduate programs at 
PSU during the 1990-1991 academic year with eleven (65\%) enrolled in master's programs and seven (35\%) studying for the doctoral degree.

Current CTA Experience

Length of time in the U.S. This varied from 7 months to 6 years. Table III illustrates details.

TABLE III

CTA'S LENGTH OF TIME IN THE U.S.

Length of Time \# of CTAs $\%$ of Sample

\begin{tabular}{llll}
\hline 6 years or less & 1 & $6 \%$ \\
5 years or less & 2 & $11 \%$ \\
4 years or less & 2 & 11 \\
3 years or less & 3 & $18 \%$ \\
2 years or less & 4 & $23 \%$ \\
1 year or less & 5 & $30 \%$ \\
\hline
\end{tabular}

Length of Time as a TA. Among these 17 CTAS, the length of time as a TA varied from only a term to 5 years. Ten of them (59\%) had taught for a year or less; two (11\%) had taught for 2 years or less; one (6\%) had taught 3 years; another one (6\%) had taught 4 years; and three (18\%) had taught for 5 years.

Department. Of the 17 CTAs in this study, 14 (82\%) taught in departments of natural and applied sciences while 3 (18\%) taught in social sciences and humanities (Table IV). 
TABLE IV

CTA DEMOGRAPHIC FEATURE BY DEPARTMENT

\begin{tabular}{llcc}
\hline Discipline & Department & $\begin{array}{c}\text { Number } \\
\text { of cTA }\end{array}$ & $\begin{array}{c}\text { \% of } \\
\text { Sample }\end{array}$ \\
\hline \multirow{4}{*}{ Natu \& Appl. } & Physics & 5 & \\
Sciences & Math & 5 & $82 \%$ \\
& Chemistry & 2 & \\
& & 2 & \\
\multirow{2}{*}{ Soc. Science } & Poli. Science & 1 & \\
\& Humanities & Foreign Lang. & 1 & $18 \%$ \\
& Music & 1 & \\
\hline
\end{tabular}

Types of TA. The CTAs were divided into three categories according to type of teaching assignment. The largest number of CTAs (10 or 59\%) were identified as laboratory-TAs, that is, CTAs who explained laboratory experiments, aims and procedures, assisted students to complete the experiments, answered questions and evaluated the laboratory reports. The second category consisted of lecture-TAs ( 5 or $30 \%$ ), those who conducted lectures, led discussions, prepared tests and evaluated students' achievements. The third and smallest category were comprised of tutor-TAs, that is, those who corrected assignments, answered lecture-related questions and assisted students to solve problems of their assignments.

Seventeen hours of taped interviews were transcribed and analyzed. The next section describes categories of the data analyzed. 
PERCEPTION OF CLASSROOM TEACHING

IN A U.S. UNIVERSITY

Based on the data, a typology was developed consisting of three categories. The first includes CTAs' impressions of U.S. professors, their teaching methods and classroom behaviors and CTAS' reactions to U.S. professors while the second category focuses on perceptions of U.S. students, including academic levels, classroom behaviors and CTAs' reactions to U.S. students. The third category, focusing on perceptions of the relationships between CTAs and students, describes how CTAs defined the relationship between CTAs and students and how they interpreted and reacted to this relationship.

\section{Perceptions of U.S. Professors}

When the respondents talked about professors, they expressed two major differences perceived by comparing U.S. professors with those in their home country: a) teaching methods and b) classroom behavior.

Teaching methods. When comparing teaching methods used by U.S. professors and by Chinese professors, respondents used such terms and phrases as "details", "focus", "step by step", "easy to follow", "use every minute of the class" and "no relaxation time for students" to describe the Chinese professors' teaching methods. The phrases that the respondents used to describe the U.S. professors were "loose schedule", "tell you everything, but 
on surface", "instruction doesn't tell much knowledge, only topics", "a lot of work to do after the class" and "give time for students to ask questions". The following quotes ${ }^{1}$ illustrate some of the differences in teaching methods:

It's different between Chinese and Americans. In the class, the (U.S.) professor gives you a lot of materials to read after the class. After the class, you get really a lot of work to do. In China, the professor gives you many details in the class, and after the class, you just need to review. But here [in the U.S.], you have to get used to the method. Another difference is that the (U.S.) professor gives time for students to ask questions. I am not used to that. It's still hard for me even after I've been here one year and a half. (F; 1.5 years; 4 terms)

I found that ...he (U.S. professor) didn't teach very much. ... He gave a very general idea.... American professors want their students to think by themselves, but chinese professors teach everything in details, especially important points. ( $M$; 1 year; 3 terms)

I feel that here (in U.S.) the classroom instruction doesn't tell you much knowledge, only topics. You have to come back to read books and articles to sum up the topics in your own way. In China, professors tell you topics step by step, and give you a summary. So you don't need to read books, only to read your notes to review the topics. (M; 9 months;

2 terms)

At another part in the interview, this same respondent commented:

In my department, there are some American professors and a professor from Taiwan. The Taiwan professor gives us a lecture in details, but American professors tell you many things and are gone, leaving those things for you to connect. But the Taiwan professor conducts his lecture step by step, and easy to follow. (M; 9 months; 2 terms) 
Classroom Behaviors. The classroom behavior of professors was the second category discussed by respondents. When describing U.S. professors' classroom behaviors, they used such phrases as "sit[s] on the desk", "put their hands and their legs on the chair" and "make jokes". In comparison with U.S. professors, the respondents described Chinese professors: "The teacher stands on the platform", "be serious", "stood between the chalkboard and the desk", and "wear[s] formal clothes". The following descriptions reflected respondents' perceptions of U.S. and Chinese professors:

In china, teaching is formal. The teacher stands on the platform. It's high. When you stand higher, you always feel yourself formal. Being a teacher is a formal status in china. But in America, professors, instructors sit on the desk, and put their hands and their legs on the chair, making jokes.... [It] is informal. When I taught first term, I was very formal and serious even though I felt confident. I stood always between the chalkboard and the desk. (M; 1.5 year; 3 terms)

I usually wear formal clothes to give students a good impression. ( $M$; 1 year; 3 terms)

In China, a teacher has a higher social status than a student. A teacher trains or teaches a student by punishment. So a teacher is always right. A student never asks questions or challenges the teacher. ( $M$; 1 year, 3 terms)

CTAS' Reactions to U.S. Professors. While perceiving the differences between U.S. and Chinese professors, some of the respondents described their reactions to U.S. professors' behavior in such phrases as "don't like that 
way" and "still not used to that" while some other respondents felt "influenced a lot". The following quotes reflected their reactions to U.S. professors' behaviors:

Some American professors and their behavior can't be distinguished from their students. Personally, I don't like that way. A teacher should behave like a teacher. (M; 1 year; 3 terms)

Personally, I like U.S. professors because they make you relax in the class, but somehow I don't like them because they don't teach much in the class. ( $\mathrm{F}$; 2.5 years; 4 terms)

[U.S.] professors give time for students to ask questions. I am not used to that. It is still hard for me even I have been here a year and a half. (F: 1.5 year; 4 terms)

[U.S.] professors influence me a lot. I consciously and unconsciously learned a lot from them. They sit on the desk, and I can do the same thing. From the second term on, I became more and more Americanized. ... But there are some shortcomings. I saw American professors coming to class late and I began to be late. (M; 1.5 years; 1 year)

When asked which teaching methods they preferred to use in their teaching, most lecture-TA respondents thought a combination of these two teaching methods as a good method. The following were some of their comments:

I suggest all Chinese TAs learn some American styles and combine them with their own style. Personally, I like Chinese teaching style because it has focus, but somehow I don't like it because it doesn't offer opportunities for students to ask questions. The teacher uses every minute of the class and there is no relaxation time for students. However, in the U.S., the teacher makes a loose schedule and 
gives time for students to ask questions. (M; 1 year; 3 terms)

My feeling is that if students ask too many questions, that would interrupt my teaching plan. However, if no students ask any questions, I would feel that students aren't cooperating with me. ( $\mathrm{M} ; 3$ years; 2 years)

My students ask questions in the class.... At the beginning, I didn't feel comfortable, but by the end, I started to feel comfortable. I like a lot of students responding to me in class, otherwise I keep talking and talking without feedback, and that makes teaching boring. ( $\mathrm{F} ; 2$ years; 4 terms)

I feel comfortable with their [students] behaviors. .... of course, sometimes, their questions interrupt the flow of my teaching, but I like that way. .... In china, teaching is scheduled. You have to finish certain chapters within a given time. However, here [U.S.] I don't need to. If I find students confused, I would spend more time on it. I don't need to speed up. It's up to me. (F; 2 years; 3 terms)

\section{Perceptions of U.S. Students}

In analyzing the data, respondents' perceptions of U.S. students are divided into four categories: a) a general view of U.S. students, b) U.S. students' academic level, c) classroom behavior, and d) the respondents' reactions to the students' behavior.

A General View of U.S. Students. The respondents discussed characteristics they perceived as strengths as well as weaknesses. When describing the students' strong points, the respondents used such phrases as "have a lot of experience", "are serious", "prefer to think and solve problems by themselves", "work under pressure", "stand a lot 
of work", and "strong in doing or creating things".

Following are some of their descriptions:

...they have a lot of practical experience. American students really work under pressure. They can stand a lot of work. They are part-time workers, some of them are full-time, and at the same time, they take two or three classes. I really think it's hard to do that, but they can do it. ( $F$; 1.5 years; 4 terms)

American students prefer to think and solve problems by themselves. ( $F$; 1 year; 1 term)

Some students study hard and they bring many difficult questions. I think American students are better at computers. Especially those students working. They find a problem at work and come to school with the problem. ( $F$; 1 year; 3 terms)

American students are much stronger than Chinese students in doing, or creating things. American students do more experiments than Chinese students. ( $M$; 3 years; 2 years)

In general, adult students are more serious in doing experiments and preparing for them than younger students who just graduated from high school. ( $M$; 0.5 year; 1 term)

When discussing students' shortcoming, CTAs used such phrases as "don't care about their studies", "never complained about their laziness", "don't spend enough time on their study", "their brains work very slow", "never think they are wrong", "don't prepare before coming to lab", and "don't think math is important". The following comments reflected their perceptions.

My impression of American students is that they don't care about their studies. One girl in my class last term got an $F$ because she didn't come to the class often and after taking 
quizzes, she never asked about her results. ( $F$; 2 years; 4 terms)

American students complain about professors' instruction if they don't study well. I had a classmate who failed many times. Whenever he failed, he said that he would like to talk to the professor about his grade. He never complained about his own laziness. He considered it's the professor who didn't teach well. (M; 9 months; 2 terms)

I think American students don't spend enough time on their studies. Some of them are good, but some of them can't be called college students by me. ( $M$; 3 years; 2 years)

What surprises me is their brains work very slow. No matter how many times you explain to them, they still don't understand. (M; 7 months; 1 term)

They [students] don't prepare before coming to lab. This kind of students is not easy to help. ( $M$; 6 years, 5 years)

If I asked them [students] to re-do their experiments, they complained about the equipment, or written instructions were not clear, or something. They never think they are wrong. (M; 6 years; 5 years)

...most American students don't think that math is important, so they don't do very well. ( $F$; 1,5 year; 1 year)

Besides a general view of U.S. students, the respondents also talked in details about U.S. students' academic levels and classroom behavior.

U.S. Students' Academic Level. Although respondents talked about U.S. students' academic level, they did not define academic level clearly. By using phrases "different academic levels", "weak in math" and "lack of basic 
knowledge of natural sciences", the respondents seemed to refer to theoretical level, specifically to mathematical

level. When talking about the mathematical level, the respondents in natural and applied sciences agreed that U.S. students were weak. Some of them described:

[U.S.] students come with different educational backgrounds. The very simple knowledge I thought they should know as college students is still unknown to them. Such a kind of thing made me very surprised at the beginning. Because I thought they would have learned that basic knowledge in high school. ... I am not familiar with students' backgrounds. (F; 1 year; 1 term)

American students are very weak in basic knowledge of natural science, especially in math. Most students in my class don't understand the course not because they don't understand the content but because of the math knowledge on which the subject content is based. This problem becomes more serious in the graduate level. ... what surprises me is that American students are much weaker in basic knowledge than they should be. (M; 3 years; 2 years)

Most American students don't know many background theories. They usually have a hard time dealing with math. ( $F$; 4 years; 7 terms)

American students are not as good as Chinese students in theories, I mean in math, physics and chemistry. ( $\mathrm{M} ; 4$ years; 4 years)

Some respondents used their experiences as examples to talk about what they meant by "weak in math" :

Every term, I have some students who do the same experiment again and again, but can't pass because they are very weak in math. Some of them didn't learn much math in high school. How can they do physics experiments at the college level? No matter how many times and what I explain to 
them, they can't understand and can't get correct answers. From my experience, the most problems students have during their experiments are math problems. Even if you tell them the formulas, they can't calculate correctly. ( $F$; 5.5 years; 5 years)

... some students asked me how to calculate fraction addition. Such a simple question should be solved by themselves at high school rather than at college. ( $M$; 0.5 year; 1 term)

I have to prepare lab experiments and math questions in order to answer their different questions, even basic high school math. ....Sometimes I think I'm not a chemistry $T A$, but a math TA. If I don't answer their questions from math, they won't understand their chemistry problems. For example, a student asked me a question $99 / 100=x / 55$. This kind of questions should be solved in the first year of high school. ( $F$; 1 year; 1 term)

....but some of them are very slow, even if you explain many times, they still don't understand because they don't have a starting point and then they are totally lost. In this situation, I have to go back and try to find where to start: high school level or college level ? Physics problem or math problem ? I have to try to find from where I should start my explanations, then students can understand me. ( $M$; 6 years; 5 years)

U.S. Students' Classroom Behavior. The respondents found that U.S. students' classroom behavior was different from Chinese students. They described Chinese students with such phrases as "quiet", "seldom ask questions", "always listen to you", "try to understand you". Major differences perceived by the respondents of U.S. students were "asking questions" and "arguing with you", "sit in the chair comfortably", "come late", "don't show up", and "drinking 
and eating". The following were some of the comments the respondents made in the interviews:

The difference $I$ find is that American students ask questions in the class, but in China students seldom ask questions in class. Even though you ask if they have questions, they are just quiet. Here [U.S.] if students don't understand, they will ask questions directly. ( $M ; 2.5$ years; 7 terms)

The Chinese professors don't like students to ask questions. However, here, the [U.S.] students are encouraged to ask questions. ... When they ask questions, they never think if it's worth asking. ... If they want to ask, they will go ahead and do it. (M; 4 years; 7 terms)

In China, I taught a big class of over 100 students. No students asked questions in the class. Even when I encouraged them to ask questions, no one asked. (M; 3 years; 2 years)

Chinese students always listen to your explanations and try to understand you, however, the American students argue with you if they don't understand. ( $M$; 0.5 year; 1 term)

When [U.S.] students don't agree with me, they begin to argue with me. I think it's oK. Arguments can help them understand materials. ( $F ; 1.5$ years, 4 terms)

...sometimes they [students] talk to each other .... Most time the students sitting at the back are those who don't study hard. They either are not interested in the course, or want to leave early. Some students sit in the chair comfortably, and I don't care as long as they listen to me. ( $\mathrm{F} ; 2$ years; 4 terms)

They [students] came to my office with food and asked me questions while drinking and eating. I don't care. I am used to that way. When I took other courses, American students ate and drank in the class, and professors didn't care. Good students behave this way, and students do the same thing. ( $M ; 9$ months; 2 terms) 


\section{CTAs' Reactions to the Students' Behaviors. Even}

though the respondents were not used to students' behavior in asking questions and arguing, their reactions to these behaviors were accepting and the phrases that they used to described their reactions were "don't bother me", "it's OK", "I feel comfortable", "don't surprise me", "I like that way", "force[s] me to prepare for the lab", "that's good". Following are some of their descriptions:

I feel comfortable with their [student] behavior. If students are quiet, I don't know if they understand or not. Do I need to repeat, or slow down, or speed up, or stop? I like to see their responses. ... of course, sometimes their questions interrupt the flow of my teaching, but I like that way. That makes my teaching easier. No questions, no communication. I want to communicate with students. If students didn't ask questions, I would get confused. ( $M ; 1.5$ years; 1 year)

Students' behavior doesn't bother me. Some of them come to class late and some of them don't show up. I think it's OK. Lab should be flexible. Some students like to work on their own, why they have to come to the lab? American students feel free to ask questions. Chinese students listen, and here [U.S.] students like to talk. Their asking questions doesn't bother me because my duty is to help them with their experiments. I like to talk with them personally face to face. When I take courses as a student, I am still not used to asking questions in class. Asking questions to interrupt professors is still hard for me. But I don't mind if other students ask questions. I don't mind my students asking me questions. ( $F$; 1.5 years; 4 terms)

Here [in U.S.], if students don't understand, they'll ask questions directly. Their habit of asking questions makes me prepare for the lab. Before I conduct a lab, I have to think what 
questions my students will ask me, then I have to prepare. Being asked questions doesn't bother me but forces me to prepare. (M; 2.5 years; 7 terms)

My students ask questions in the class. Actually, that's good even though some questions are really simple. At least they let me know where they have problems. I feel comfortable when they ask questions. ...I like a lot of students responding to me in the class, otherwise I keep talking and talking, and that makes teaching boring. ( $F$; 2 years; 4 terms)

My feeling is if students asked too many questions, that would interrupt my teaching plan. However, if no students ask questions in the class, I would feel that students aren't cooperating with me. ( $M$; 3 years; 2 year)

Actually, the respondents talked a lot about their feelings of liking students to ask questions in the class. In fact, they considered "asking question" as a normal behavior. If there were no question-asking, they felt that "students don't cooperate", or "makes teaching boring" or "I would get confused", or even "no communication".

Two major reasons for CTAS' positive reactions to question-asking in class emerged in the data: a) They had opportunities to contact Americans in China before coming to the U.S.; and b) the length of time staying in the U.S. helped them have a better understanding of U.S. values, beliefs and norms. The following were some of their explanations:

I am not surprised at [U.S.] students' behavior. Because now China is open and we get to know Americans more and more. In China, I had some 
American friends, so I got some ideas about how Americans behave. (M; 1.5 years; 1 year)

Before I came to the U.S., I knew something about Americans' behavior. Their behavior is different from the chinese. Whatever they do, I'm not surprised because that's their way. (M; 4 years; 7 terms)

In fact, [U.S.] professors like their students to ask questions. In China, the students' questions mean no respect for teachers. In the U.S. if students don't ask questions, the professors don't know what to do. ( $M$; 1 year;

3 terms)

I always keep in mind that equality is an American principle. ...students ask questions and challenge the teacher. In China, the teacher has a higher social status than a student. The teacher trains or teaches by punishments. So the teacher is always right. ( $F$; 3 years; 2 years)

Perceptions of the Relationships Between CTAs and students When talking about their relationships with the students, the respondents could not precisely define what the relationship was. However, they were able to distinguish that it "was not the same as in China". They viewed the Chinese teacher-student relationship as a formal one and relationships of Chinese friends as informal. Respondents felt their relationship with American students seemed to lie between friends and teacher-student relationships. The following comments reflect their perceptions:

We [CTA and students] are not friend relations, not as Chinese teacher-student relationship, either. I don't feel I have a higher status than the students. We are not close friends. 
It's hard to say what the relationship is. ... When I was a TA in China, the students called me teacher and I had to act like a teacher in the Chinese norm. Here [U.S.] everyone is the same. (M; 0.5 year; 1 term)

Even though I have been in the U.S. more than a year, I am still thinking what a proper relationship between teacher and students is. (M; 1.5 years; 1 year)

I think it's a regular relationship. They [students] ask questions and $I$ answer. There isn't a personal relationship involved. (F; 1.5 years; 4 terms)

The relationship with students in U.S. is more informal than that in China. In China, there is a big distinction between teacher and students. Here, the distinction isn't clear. (F; 1 years; 1 term)

I think my relationship with the students is between friends and teacher-student relations. Not very formal, not very informal. I am sometimes very serious, and sometimes very casual. (M; 3 years; 2 years)

Some respondents perceived that their relationship with the students was based on their academic qualification, not on their TA positions. They seemed to believe that if they could help students solve academic problems, they would gain "respect" and "trust" from the students.

The students respect me not because I am a TA, but because I can always answer their questions and explain why their answers were wrong. (F; 5 years; 5 years)

The students respect me. They showed their respect to me from the very beginning. If you can answer first a few questions beautifully, they will trust you and think you can answer all questions. (M; 9 months; 2 terms) 
After a term as a TA, my students trust me because I can answer all of their questions. Some of them asked me to be their tutor after class to help them with their math and physics (F; 5 years; 5 years)

CTAS' Reactions to TA-Student Relationships. When talking about reactions to their relationships with students, most of the respondents described: "it's very good", "I prefer the relationship here [U.S.]" and "We don't feel uncomfortable". They believed that "if I treated students nicely, they would treat me nicely" (M; 1 year; 2 term). Some of them talked about their experiences of dealing with the students.

I prefer the relationship here [U.S.]. I like casual relationships. ... I don't want to be serious in the class, but sometimes it's difficult for me because I don't speak English very well. I can't make jokes in the class. But I try my best. I show them that I am willing to help them. (F; 2 years; 1 year)

I feel good if students come to see me and ask questions. I really want them to talk with me not only the language but also something about chinese culture. ( $\mathrm{M} ; 1.5$ years; 1 year)

The first term, I was very formal in the class, but after the second term, I changed a lot and tried to be informal. I made jokes and smiled, but still more formal than American professors. Now in the class, both I and my students feel oK. We don't feel uncomfortable. We don't create anything formal or informal. We co-operate pretty well and everything comes naturally. (M; 1.5 years; 1 year)

I am a TA and a student as well. When I talked with my professor, I always felt nervous. So I can imagine my students' feelings. When they ask questions, I am very patient to answer their 
questions and explain again and again until they understand. ( $F ; 2$ years; 4 terms)

You [TA] have to be very patient to the students and pay attention to their questions, then they will be happy. If someone asks you a question, you have to stop your teaching and answer his question. ( $\mathrm{F} ; 3$ years; 4 terms)

\section{Summary}

Chinese TAs described their perceptions of three areas of the U.S. university classroom in the interviews: professors, students and TA-student relationships. These perceptions reflected cultural differences in perceiving classroom communication. These perceptions of differences between U.S and Chinese professors and students might cause communication problems in the classroom. In the nest section, communication problems between CTAs and U.S. students are discussed.

\section{IDENTIFICATION OF COMMUNICATION PROBLEMS}

In analyzing the data, another typology, Identification of Communication Problems, emerged with three categories. The first describes Chinese TAs' (CTA) perceptions of communication problems. The second category, Internal Attributions, discusses CTAs as a source of communication problems, that is, their lack of language proficiency, lack of confidence, and unfamiliarity with the U.S. university. The third category focuses on external attributions, describing students' academic levels and institutional 
structural features as another source of communication problems.

\section{Communication Problems}

The respondents participating in this study acknowledged that communication problems exist between CTAs and students. The reality of the problem, as the respondents interpreted it, lay somewhere in between CTAs and students. Chinese TAs' general perceptions of communication problems were: "communication is a big problem", "language is a fundamental problem", CTAs' "unfamiliarity with the U.S. university", "American students are very weak in math" and "communication problems should be considered from two sides." The following comments reflected CTAs' general perceptions of communication problems :

I think communication is a big problem. Even if you know the subject and materials very well, sometimes you still can't understand them [students]. (F; 1.5 years; 4 terms)

Language is a fundamental problem. Another problem is information about American students. ...I am not familiar with students' backgrounds. ( $F ; 2$ years; 4 terms)

The most difficult thing to me, I think, is the communication problem. ... so sometimes, I find myself in a very difficult situation in giving students a clear idea. ( $F$; 1 year; 1 term)

There are some difficulties in communicating with the students since English is not my native language. ( $M$; 1.5 years; 1 year) 
I think the communication barrier between TAs and students is not only language, but also expectations of academic levels of students.

( $F ; 5.5$ years; 5 years)

... American students are very weak in math. ... [they] don't understand my answers not because of my language, but because their level is too

low to understand my explanations. Even American professors don't know how to deal with such students. ( $M$; 3 years; 2 years)

These comments reflected the respondents' perspective on the communication problem. They attributed the problem to both internal and external factors. Internal factors refer to CTAs themselves and external factors include U.S. students and structured feathers. The next section will discuss these attributions.

\section{Internal Attributions}

The respondents explained that communication problem partly stem from CTAs themselves due to their lack of English proficiency, lack of confidence teaching in a new situation, and unfamiliarity with the U.S. university.

Language Proficiency. English proficiency was one of the internal attributions which the respondents described in the interviews. Although all the CTAs in this study learned English in China from one to ten years and received a TOEFL score of 550 or better before they were employed as TAs, their English competence was still less than perfect. They described their language difficulties: 
The problem of communicating with students is language, especially at the very beginning. Since English is not my native language, it's difficult for the first term. The difficulty I had in the first term was language problem. I could understand what they [students] said, but they couldn't understand what I said. (M; 4 years; 4 years)

The main problem is communication, the language problem. Contents and topics are not big problems. Language is really a problem. The first term, I had a hard time understanding students. That's a language problem, not a content problem. ( $F ; 5.5$ years; 5 years)

Analysis of the data revealed six specific language problems: pronunciation, accent, vocabulary, American slang, rate of speaking, and grammar-ruled English vs. idiomatic English. The following were some of respondents' descriptions about language difficulties:

Pronunciation is a problem. However, when your students get to used to your pronunciation, there is no problem. But you have to speak key words very clearly. ( $F$; 2 years; 1 year)

In the first term, the most difficult is language. Because we learned English in China, it is British English. Additionally each person has his own accent. Therefore, sometimes when Americans are not used to the accent, even a single word's pronunciation will block understanding. ( $M$; 1 year; 3 terms)

Another problem is words because my vocabulary is limited. So sometimes, I find myself in a very difficult situation to give students a clear idea. It's hard for me to express myself. ( $F$; 1.5 years; 4 terms)

I find American English is hard to understand because there is much slang. (M; 9 months; 2 terms) 
In the first term, when students asked me questions, they spoke too fast, I couldn't separate one word from the others, and then I was totally lost. (F; 2.5 years; 4 terms)

Language is a fundamental problem. ... I learned English in China with grammar or sentence structure as focus. However, American students speak English which doesn't follow the grammar rules. When this happens, I can't understand them. ( $F ; 1$ year; 1 term)

Lack of Confidence. Another source of difficulty identified by the CTA was lack of confidence teaching in a new situation. Although 11 (65\%) of the respondents had taught in China from one to five years, when they began to teach in a U.S. university, facing American students and speaking English, they felt "very nervous", "not confident", and "not relaxed", especially in the first term.

In the first term, I felt very nervous about teaching in the class even though I had some teaching experience in China. I was not confident. When students asked me questions, I was not sure if I understood them.

(M;

1 year; 3 terms)

The first term TA has many difficulties because you are a newcomer. Even if the content is nothing, you have to be familiar with everything. After being a TA for a term, I feel better because I am familiar with the lab equipment and lab work. ( $M$; 6 years; 5 years)

At the beginning, when students asked me questions, I sometimes didn't understand them. It's because some rules I didn't know. It isn't lab work, or the content, or language. It's kind of experience. After first term, I feel better and better because I got to know everything. Every term, students have almost the same questions. After repeating and repeating the same questions, I don't have any problems. ( $\mathrm{F} ; 4$ years; 4 years) 
Another thing is that I wasn't relaxed about teaching. When I taught for the first time, I felt very nervous. Although I had teaching experience in China and I was never nervous even in front of a big audience, I felt nervous when I spoke a different language. (M; 3 years; 2 years)

I didn't feel confident when I taught first term. I didn't want any questions because I was so nervous. When I am nervous, I can't understand anything, even in china. I forgot how to speak English. I forgot words. They were in my month, but I didn't know how to say them. After teaching a term, I started to feel confident about teaching. Also I started to know the materials and the students' backgrounds. I felt better. (F; 2 years; 4 terms)

For communication, in the first term, I had a little trouble understanding their questions because I wasn't that confident. So when they asked me questions, I was nervous. The more nervous I was, the less I understood them. ( $F$; 2 years; 1 year)

Unfamiliarity with the U.S. University. Another internal attribution was CTAs' unfamiliarity with the U.S. university. Chinese TAs' perceptions of the academic level of students and educational values are different from those they had expected. The following were some of their comments on the unfamiliarity:

In China, I taught at a college and I knew the academic level of the students: what they learned at high school. So I was clear what they already knew and what they should learn. However, in the U.S., the students come from different educational backgrounds. Much simple knowledge I thought they should know as college students is still unknown to them. I have to figure out what they have learned and what they need to learn. I am not familiar with students' backgrounds. ( $F$; 1 year; 1 term) 
Based on my personal experience as a TA for four years, I think the communication barrier between TA's and students is not only language, but also expectation of academic level of American students. If a student even doesn't know how to do with $2 / 3-3 / 5$, the TA feel very frustrated. ( $F$; 5.5 years; 5 years)

When I taught in the first term, I didn't realize it is a very low class even though almost all the students in my class are science majors. I expected too much. ( $F ; 1.5$ years; 4 terms)

In the first term, I didn't know general teaching rules, how to communicate with students, how to grade, how to help students, especially in math, and how to conduct a class and $\mathrm{a}$ lab. ( $\mathrm{F} ; 1.5$ years; 1 year)

In sum, the internal attributions of the problem which the respondents perceived and interpreted were their language proficiency (pronunciation, accent, vocabulary, expressions, speed of speaking), their lack of confidence teaching in a new situation and their unfamiliarity with the U.S. university. These internal factors may become communication barriers in their interactions with students.

\section{External Attributions}

In addition to identifying the internal attributions of communication difficulties, informants suggested two external attributions: the students themselves and institutional structural features.

\section{Students' Academic Level. U.S. students' academic}

level was thought of as an important external attribution of the classroom communication problems. Academic Level, as described in the previous section of this chapter, referred 
to math ability. Some participants felt "very frustrated" with students' low academic ability. The following descriptions revealed their frustration in communicating with students.

...most American students are very weak in math. Their questions are related to not only to physical knowledge, but to math as well. ... So when I answer their questions, I explain to them not only physics but also math. Sometimes, they can't solve a simple problem, for example, $2 x=3$. Such a low level of math can't help them understand physical problem. When I explain to them their problems, they can't follow or understand my explanation. ... Indeed, there is language problem, this is one side, the other side is American students are too weak in math to take college physics. Therefore, the communication problem between students and TA's has these two possibilities. (F; 5.5 years; 5 years)

Sometimes, students don't understand my answers not because of my language, but because their academic level is too low to understand my explanations. (M; 3 years; 2 years)

Sometimes, there is a misunderstanding between me and students about their questions. This is not only because of language, but because the way to understand the questions. (F; 2 years; 4 terms)

Two additional structural features were seen as contributing to some of the CTA-student communication difficulties: a) unclear explanations in the "Experiment Manual", and b) sequencing of laboratory experiments in relation to classroom instruction.

The manual here has no focus, gives very general ideas. It should tell how to use lab equipment so that students can use them in their 
experiments. Most American students don't know how to use the equipment and ask TA's to tell them. (M; 0.5 year; 1 term)

Sometimes, when lab experiments go ahead of class teaching, students will have a lot of questions and I have to answer more questions than I need. When this happens, I have to answer their basic math questions, which is beyond my field. So I have to prepare lab experiments and math in order to answer their different questions. ( $F$; 1 year; 1 term)

Another thing is that lab experiments and course content are not coherent. Sometimes, course teaching is behind lab, then students have more questions. I have to explain to them about the course content. ( $F$; 5.5 years; 5 years)

\section{Summary}

The respondents perceived communication problems between CTAs and students as having two sources. Both CTAs' difficulties, as internal attributions, and students' academic difficulty and institutional structural features, as external attributions, were identified as the causes of breakdowns in communication. Facing the communication problems, CTAs tried to solve them. The next section describes problem-solving strategies CTAs employed to repair breakdowns in their communication with students.

\section{CTAS' PROBLEM-SOLVING STRATEGIES}

Chinese teaching assistants (CTA) adopted specific strategies to manage and solve communication problems they encountered. These included a) working with other TAs; b) preparing before teaching; c) using non-verbal behavior; 4) 
adjusting teaching methods; and 5) efforts toward becoming familiar with U.S. students.

\section{Working with other TAS}

Working with other TAs as a team was one of CTAs' problem-solving strategies. The respondents thought that the first term teaching was the most difficult for CTAs and that it would be a great help to work with experienced TAs. During co-teaching, lecture-TAs observed a class which they would teach before they began to instruct students;

laboratory- and tutor-TAs worked with other TAs as regular TAs in the first term and started to work by themselves beginning second term. After this transitional period, CTAs "felt better", "confident", and "there is no problem."

Informants cited three advantages. First, they could get experience by observing experienced TA's and doing experiments with other TAs' help. Second, they felt more comfortable solving teaching problems among their peers rather than talking with the professors or supervisors because they believed the peers understood each other better due to the same teaching positions, and because they did not lose face in front of their supervisors. Third, they did not feel so isolated in cases of facing communication difficulties because TAs could help each other. 
Preparing Before Teaching

Another strategy adopted by CTAs was preparing before teaching. Preparation includes such activities as getting ideas about the subject content, doing all experiments and assignments, even writing experiment reports, step by step, and remembering the results. This preparation helped CTAs feel confident in front of students and enable them to concentrate on listening to students' questions. Some respondents commented:

When I was a TA first term, I tutored students. .... I had to read through the text to get ideas about the content and do all the assignments so as to be familiar with solutions. So when students came to ask me, all their questions were within my expectations. Because I have this confidence, I don't find language is a problem. (M; 9 months; 2 terms)

I did the experiments by myself from the beginning to the end, and even the results numbers $I$ kept in my mind. Because different students will ask you different questions, you have to answer their (students) different questions in a few minutes. ( $M$; 0.5 year; 1 term)

Go to the lab and be familiar with all the experiments and the procedure. ...Also, write the reports yourself and be familiar with every step and the result because you have to check their report and result right after they finish each step. ( $F ; 1$ year; 1 term)

The respondents also found that preparation could help them anticipate potential content difficulties. One of them made such a comment:

Teaching a class is more difficult than taking a class. Even though you know the content and 
topic, it doesn't mean that you can make your students understand. ... I spend time preparing. I have to know which parts are hard for students and which parts are easy. When I teach the hard part, I will spend as much time as I can to explain and give more examples for students to understand. If it's the easy part, I will go quickly. (F; 2 years; 4 terms)

\section{Use of Non-Verbal Behavior}

Chinese TAs, realizing that their less than perfect control of English might be a cause of misunderstandings between themselves and students, used specific non-verbal behavior to help them communicate with students. One respondent talked about his experience of using a pen, paper and gestures as supplements during his explanations to students.

I can use a pen, or paper or chalkboard, or gesture to explain to them [students]. ... When I answer students' questions or explain to them, I not only use my words, but my pen, paper, and arms to help. (M; 0.5 year; 1 term)

Most respondents agreed that words only delivered ideas while non-verbal behavior carried emotions and feelings, and that communication was more than just an exchange of information but needed exchanges of feelings. They tried to use non-verbal actions such as smiling and eye-contact to express their willingness to help students and to show their concern about students. This kind of concern and willingness was seldom expressed clearly by verbal messages, partly because of their language barriers. The following 
were some of the respondents' comments on their experience of using non-verbal behavior to communicate with their students in the classroom:

I smile a lot and try to make them [students] feel easier. If you look serious, they will feel more serious. I try to do my best to make them relax in the class. It's difficult for a foreigner to make a joke, however, you can smile. ( $F$; 2 years; 1 year)

[I] look at their [students'] facial expressions. Some of them show their confusion, then [I] have to stop and find out their problems or repeat what I said. ( $F ; 2$ years; 4 terms)

Some respondents used paralanguage behavior to manage communication problems. Some of them talked about adapting their speech rate to manage a communication problem:

When I teach, I try to speak slowly. I give spare time for students to think. (F; 2 years; 1 year)

Some students, especially young students, speak too fast for me to understand, then I ask them to slow down. When I speak slowly indicating I am a foreigner, they automatically slow down. (M; 9 months; 2 terms)

Another respondent, paying attention to enunciation, tried to "speak key words and terms very clearly" in his lectures. (M; 1 year; 3 terms)

Teaching Method Adaptation

Employing different teaching methods in different instructional settings was another strategy used by CTAs in order to avoid breakdowns in communication. Some CTAs 
"repeat the important points again and again" (M; 1 year; 3 terms); some spent more time on difficult points: "If I find students confused, I would spend more time on it. I don't need to speed up" (F; 2 years; 1 year); and others reported giving additional examples to support their explanations.

What $I$ do is to try to give them [students] enough examples to help them with their homework and understand the contents. ( $F$; 2 years; 4 terms)

When I explain to students, sometimes, there are language barriers. If such a thing happens, I would give more examples to express my ideas. That works. (M; 1 year; 3 terms)

In the class, I try to give them some new examples which the texts don't say. Those examples can make students understand theories better. The examples are from my experience, which would increase their interest in learning. (M; 3 years; 2 year)

Writing down key points and words on the board was also perceived as helpful to deliver their ideas and facilitate students' understanding.

Before I conduct a lab, I always give students 10 to 15 minutes introduction. I like to write down key points on the board so that students can read in case they don't understand me. ( $F$; 1 year; 3 term)

In the class, I like to give students not only verbal explanations, but also written notes on the board. Because sometimes I am afraid that they won't understand me orally, I write down what I said on the board. In this way they know what I am talking about and what is important. ( $F$; 2 years; 4 terms) 
Another respondent believed that meanings could be figured out from discourse in spite of some language barriers. His strategy was "a complete idea."

When teaching, I try to finish a whole sentence to give students a complete idea about what $I$ want to say. ... When I teach, I try to keep talking rather than stopping to think of a word $I$ want to use. ( $F$; 2 years; 1 year)

Still another respondent tried to use words and terms that students use in order to obtain a better understanding between them and students.

I paid more attention to terms. For example, I used to say "go up a step". The American students are used to saying "raise a step". so I try to adjust my words to theirs. If you use the words American students are familiar with, they will understand you better. (M; 1 year; 3 terms)

Connecting topics of subject matter logically was another strategy employed by CTAs. One of the respondents said:

I try to use connections between different topics. Because everything is logical to me, but not really to the students. The connection will help them to move from one point to another easily. ( $F ; 2$ years; 1 year)

When students asked questions during the lecture, CTAs listened first, then decided what to do. Most CTAs were happy to answer questions which were related to the topics, however, they did not like unrelated questions to interrupt 
their instruction plans. One respondent described how he dealt with students' questions in the lecture:

When students asked questions, I tried to explain to them. Some American students asked strange questions and I couldn't answer in two or three words. Then I would tell them that they would learn it later. Some American students asked questions which had nothing to do with the content of the class. In this case, I never argue with them, rather, I told them the questions were ahead of the class. I tried to find reasonable excuses to avoid answering their strange questions and delaying my teaching plan. (M; 3 years; 2 years )

In laboratory and tutoring settings, CTAs encountered a variety of questions from students with different mathematical backgrounds. When facing such a situation, CTAs tried to figure out what the student's "stuck point" was, and then started the explanation from that point; or they divided the question into several "small questions" and then explained it step by step. Only in this way could both CTAs and students have a "shared language" for the questions.

When the student didn't understand my explanation, what I had to do was to try to find his starting point of understanding. Because different students are at different levels. (M; 6 years; 5 years)

What I did in helping with their [students] questions is to divide their complete questions into small questions and tell them the backgrounds of the small questions, and the connections. In this way, students have a whole picture of their questions. (M; 0.5 year; 1 term) 
Efforts Toward Becoming Familiar with U.S. Students

After interacting with U.S. students, CTAs got to know something about U.S. students, their academic backgrounds, classroom behavior, educational goals and general values. These perceptions enabled them to be aware of and sensitive to the differences between U.S. students and students of their home country. The respondents realized and talked about the importance of perceiving the cultural differences and understanding U.S. students. Becoming familiar with U.S. students was thought by CTAs to be an important strategy for managing communication problems. When they prepared for their lectures or laboratory instructions, they considered not only the content, but students' educational background as well. Some respondents described preparing their teaching.

When I conduct a lab, I have to get to know the students about what they learned in high school and what kind of problems they may have. To prepare a lab doesn't mean to prepare the contents only. The students' academic levels are quite different. (M; 4 years; 4 years)

I spend more time preparing before class. Now I have experience at teaching this class, I know which parts are hard for students and which parts are easy. When I teach the hard parts, I will spend as much time as I can to explain and give more examples for students to understand. If it's easy parts, I just go quickly. (F; 1.5 years; 4 terms)

Besides preparing for the contents and students' academic levels, CTAs also paid much attention to students' 
feedback during their communication, because the feedback from the students indicated whether the communication went well or broke down, and showed how much the students knew about the topics. Being patient and paying attention to feedback provided access to getting to know U.S. students.

You have to be very patient to students and pay attention to their questions. .... If you want them to be active, you have to ask them questions. You have to look at their facial expressions. Some of them show their confusion, then, you have to stop and find out what their problems are, or repeat what you said. ( $F$; 2 years; 1 year)

The strategy of getting to know U.S. students was perceived as helping CTAs in their communication with the students. They found that the more they knew about U.S. students, the easier the communication became. As several informants commented:

After being a TA for several years, I know American students better and better. I can tell exactly what problems the students will have at a certain level, then answer their questions immediately. They are happy and I am happy too. There is no problem between me and the students. Communication is easy. ( $M$; 6 years; 5 years)

After the first term, I got experience with teaching in the American classroom and familiar with students and course content and I felt confident. ... Now everything is in my mind. (M; 2.5 years; 7 terms)

They [students] don't need to ask me questions verbally, they only point out the place they are stuck, then I can figure out what problems they have. ...I read the textbook... and do all the assignments...so when students come to me, all their questions are within my expectation. 
Because I have this confidence, I don't find language was a problem. (M; 9 months; 2 terms)

\section{Summary}

The respondents described the strategies which they employed to prevent as well as repair breakdowns in communication. Chinese TAs tried to manage language difficulties by using non-verbal behavior strategically and preparing before teaching. By using strategies of adjusting their teaching methods and becoming familiar with U.S. students, CTAs tried to manage cultural difficulties. These strategies were considered to be helpful in managing communication with U.S. students.

\section{ATTITUDES TOWARD THE TA POSITION}

In the interviews, the respondents described satisfaction with the TA position although they had a difficult time communicating with U.S. students. Data analysis suggested 5 categories of satisfaction associated with being a teaching assistant: a) gaining teaching experience, b) improving one's English, c) learning through teaching, d) understanding U.S. students and e) making friends.

\section{Getting Teaching Experience}

The Chinese TAs were proud of teaching in a U.S. university because not many people could get this 
opportunity and only top students could be employed as TAs. The following were some of their comments:

[It's] interesting. I can get experience teaching in America and get opportunity to communication with American students and understand them. ( $F ; 1.5$ years; 4 terms)

I like this position. Since $I$ was a teacher in China, I like teaching very much. I like to be with students. ( $F ; 5.5$ years; 5 years)

Improving one's English

Having the opportunity to practice speaking English was another reason given for job satisfaction. The respondents talked about their English improvement with these comments:

I have a good opportunity to practice English. (Mi 1.5 years; 1 year)

My English improved a lot because of talking with students. ( $F$; 2 years; 1 year)

I can get at least four hours each week to practice English. ( $M$; 4 years; 7 terms)

My English is getting better and better. (M; 3 years; 2 years)

Being a TA helps me with my English. I can speak English much better now than the first term. ( $F ; 3$ years; 4 terms)

Learning Through Teaching

The respondents found that they learned something new about their discipline through teaching. Some respondents described:

...being a TA forces me to prepare labs, so I have to do some experiments myself. Then I 
learned something I didn't know or something I was not clear. ( $M$; 0.5 year; 1 term)

Most experiments I did in China but in different ways. When I was a first term TA, I worked together with another TA who has some experience. I learned from her about how to do experiments in a different way. ( $F$; 5 years; 5 years)

Some other respondents talked about their experience of learning from students by arguing with them:

When the students argue with me, it's ok to me. Sometimes, I make mistakes and they [students] understand problems better than me. After arguing with students, both of us are more clear about the problem. If I am wrong, I will say I am wrong because this is science and everyone should respect truth. Arguments help me get a sound foundation in my field. (M; 2.5 years; 7 terms)

When students don't agree with me, they begin to argue with me. ... Argument can help me understand materials. ( $F ; 1.5$ years; 4 terms)

\section{Understanding U.S. Students}

The TA position provided a good opportunity for the respondents to get to know U.S. students, to be aware of and sensitive to the cultural differences and to appreciate different cultures. After interacting with U.S. students, they felt they understood U.S. students better. The following comments reflected how interactions with students helped CTAs perceive students:

...to know cultural differences between America and China, then you can understand why American students do what they do. The big difference between chinese students and American students is Chinese students are 
quiet and they listen to you. They show respect to you. But here [U.S.], they [U.S. students] grow up with equality, so they can argue with you and sometimes anything can happen. (F; 1.5 years; 4 terms)

There is a big difference between the first term $I$ was a TA and now. The difference is that I have a better communication with students.

Whatever they say or I say, we understand better. (M; 4 years; 4 years)

American students are not as good as Chinese students in theories. But American students are better than Chinese students in computers. They are different. (M; 3 years; 2 years)

American students are much stronger than Chinese students in doing or creating things. (F; 1.5 years; 4 terms)

\section{Making Friends}

The TA position offered Chinese TAs a "chance to know a lot of people and make friends" (F; 1 year; 1 term). One respondent, taking the same class with his students, described that he and his students "learned with and from each other, and then became friends" ( $M$; 3 years; 2 years). Another respondent who had a close relationship with students reported:

Being a TA in an American university, I get an opportunity to know a lot of people and to make friends. ... [they] asked me to be their tutors. Sometimes, I got more than I could handle. (M; 4 years; 4 years) 


\section{SUMMARY}

This chapter has described CTAs' perceptions of the U.S. university in general and U.S. professors, U.S. students and teacher-student relationships specifically. These perceptions reflect cultural differences in expectations of classroom communication.

From their perspective, CTAs perceived that U.S. professors "sit on the desk", "make jokes", "even drink", "give time for students to ask questions", and that the teaching methods were "general ideas", "on surface", "only topics", "don't teach much","a lot of work to do after the class" and "loose schedule". In contrast, CTAs' perceptions of Chinese professors were that they "stand between the chalkboard and the desk", "wear formal clothes", "use every minute to teach", "have higher status", and are "always right" and the teaching methods used by chinese professors included "details", "focus", "step by step", "easy to follow" and "no relaxing time for students".

CTAS' perceptions of U.S. students were that they "have a lot of experience", "prefer to think and solve problems themselves", "work under pressure", "strong in doing and creating things", but they "don't care about their studies", "come late," "eat and drink in the class", "ask questions", "argue with you", "never complain about themselves", are "weak in math" and "lack of basic knowledge of natural science." In comparison with U.S. students, Chinese 
students "don't interrupt", "don't challenge", "don't correct professors' mistakes", "seldom ask questions", and they "listen to you", "try to understand you" and are "quiet", "in the same academic level", and are "good at theories".

The respondents used such phrases to describe U.S. teacher-student relationships as "casual", "informal", "everyone is the same", "equality"; "distinction isn't clear" while the phrases used to describe the chinese teacher-student relationship were "formal," "serious," "stable," "respect," "trust", "a big distinction".

These perceived differences between U.S. and Chinese professors and students might cause communication problems in the classroom. The respondents identified both internal and external sources of communication problems. The internal sources refer to CTAs' language, cultural and selfconfidence difficulties while the external sources include U.S. students' academic abilities and institutional structural features.

Facing communication problems, CTAs employed several problem-solving strategies to prevent and repair breakdowns in communication. These strategies included working with other TAs, preparing before teaching, strategic use of nonverbal behavior, teaching method adaptation, and efforts toward becoming familiar with U.S. students. The 
respondents found that these strategies helped them manage classroom interactions.

In summary, during the interviews the respondents talked about their experiences and perceptions of being TAs in a U.S. university, identifying communication problems, dealing with the problems and being satisfied with the work. From the data emerged a communication pattern among Chinese TAs in a U.S. university and a process of CTAS' adjustment to classroom communication in a U.S. university. Chapter V summarizes the study findings, discusses study strengths and Iimitations as well as recommends future directions in ITA research.

\section{ENDNOTE}

1. After each quote of this chapter, $F / M$ refers to female/male; the first number stands for the length of time in the U.S.; and the second number stands for the length of time as a TA. 
CHAPTER V

\section{DISCUSSION AND CONCLUSION}

As described in Chapter I\& II, issues related to international teaching assistants and ITA training programs have been studied by many researchers and post secondary institutions. This study took Chinese teaching assistants (CTA) who taught at Portland State University during 19901991 as a case to explore CTAs' communication experiences in the U.S. university classroom from their perspective. Based on the findings presented in Chapter Four, this chapter further analyzes CTAS' descriptions of their communication experiences in the U.S. university classroom and relates findings to prior research on the subject and theoretical perspectives of this study. The chapter also discusses CTAS' adaptation to the U.S. university classroom and implication of the findings for ITA training programs. Finally, limitations of this study and future research directions are discussed.

\section{CTAS' CLASSROOM COMMUNICATION}

IN A U.S. UNIVERSITY

Throughout the interviews Chinese TAs (CTA) talked about the classroom communication they expected and experienced both in China and in the United States. The 
classroom communication that CTAs talked about consists of such components as language, classroom behavior, pedagogical skills, academic expectation and educational values. CTAs participating in this study described three factors which affect their classroom communication: language, cultural expectations of the classroom setting and students' academic capabilities.

\section{Language}

Most CTAs participating in this study agreed that less than perfect mastery of English affected their communication with U.S. students, especially first term of teaching in a U.S. university. Their own experiences revealed that although all of them had learned English before they came to the U.S. and they had all passed the TOEFL examination with a score 550 or higher before they were hired as TAs (see CTA demographic data, p. 46), their language competence was still not sufficiently adequate for the U.S. university classroom communication.

Two main reasons were given in the interviews. First, English taught in China focused on grammar and reading rather than on conversational communication, so CTAs could not understand U.S. students because they found that students' conversation did not "follow the grammar rules" (F; 1 year; 1 term). Second, the TOEFL examination tests only written skills, so a score of 550 or higher does not reflect the oral ability of the test-taker; in other words, 
a passing TOEFL score does not indicate being able to communicate orally. One of the respondents described her experience:

Before I came to the U.S. I couldn't speak English at all. Even though I passed TOEFL, that doesn't mean I can speak English. You can get a very high TOEFL score, but still can't speak English, because TOEFL tests grammar and reading, not speaking. Speaking requires practice. When I came to the U.S. I tried to practice my English. ( $F ; 2$ years; 1 year)

As English language producers in the classroom communication, Chinese TAs perceived they had six major language difficulties: pronunciation, accent, vocabulary, fluency of speaking, American slang, and idiomatic English. Prior research indicates that international TAs' language difficulties such as "poor English", "heavy accent" and pronunciation (Hinofotis \& Bailey, 1980; Dunkel \& Rahman, 1987; Yule \& Hoffman, 1990; and Byrd \& Constanindes, 1988) are viewed by students, as the language receivers in the classroom, as contributing to miscommunication between teachers and students. A comparison of the different areas of language difficulties viewed from the producers' and receivers' perspectives reveals that CTAs encounter not only linguistic difficulties, such as pronunciation and vocabulary, not also difficulties of English usage in the U.S. university undergraduate classroom, e.g., American slang and idiomatic expressions of American English. The comparison also reveals that students evaluate ITAs' English 
language proficiency by examining their linguistic forms (pronunciation, vocabulary, etc.) while CTAs in this study view their language difficulties by looking at overall ability including linguistic performance and communication competence (English usage and ways to perform language). The interview data in this study suggest that CTAs' language difficulties are more than "heavy accent" and "poor English", and that both language skills and usages need to receive attention in ITA training programs.

\section{Cultural Expectations of Classroom setting}

The respondents' descriptions of their experiences in the U.S. university indicated that cultural factors affected CTAs' classroom communication. Culture is a collection of structured expectation by which its members construct, test, modify their interpretations of discourse and the other's purposes as inferred through the discourse that is acquired often informally in and through experience (Ehrenhaus, 1983). Chinese TAs did their undergraduate studies in china and the university classroom setting consisted of a particular set of student behaviors and teacher behaviors considered appropriate in that educational setting. These can be summarized as follows. Chinese professors dress formally and stand between the chalkboard and the desk while conducting their teaching; Chinese students are quiet in the classroom without challenging, interrupting, correcting 
professors' mistakes, or asking questions; instead, they always listen to and try to understand the professors.

The Chinese post-secondary education focuses on information-giving, memorization of known truths and theoryoriented learning. Consistent with this educational emphasis is the teaching method dominant in the chinese classroom, that is, the professor uses every minute to present, step by step, information that students can easily follow. This teacher-centered approach and specific teaching method is considered appropriate in the chinese educational setting, supporting the existing educational values.

In China, students never ask questions in the class. Questions mean not respect to the teacher. American students feel free to ask questions. (M; 1 year; 3 terms)

The Chinese teacher teaches students by punishments. So the teacher is always right. students cooperate and never challenge the teacher. (M; 6 years; 5 years)

When I taught in China, my students were quiet and 1 istened. Even I gave them opportunities to ask questions, they didn't ask. Asking questions to interrupt the teacher are hard for them. ( $F$; 2 years; 6 terms)

The forgoing clearly contrasts with what CTAs' experienced when they taught in the U.S. university classroom. Interview data suggest that it was CTAs' undergraduate experiences in China which structured their cultural expectations of the U.S. university classroom setting. 
Chinese TAs described in the interviews their perceptions of U.S. professors and students. The professors sit on the desk and make jokes while they are teaching; U.S. students prefer to think and solve problems themselves but don't care about their studies and they come to the class late, eat and drink in the class, ask questions and even argue with professors.

U.S. higher education values creative thinking and problem-solving (Constantinides \& Byrd, 1986), thus, the teaching methods dominant in the U.S. classroom are quite different from Chinese teaching methods. Chinese TAs perceived that U.S. professors introduce general ideas of each topic and leave details for students to study and think about for themselves, and their classroom teaching is flexible so that students have opportunities to ask questions and discuss content with their peer and professors. However, when CTAs conducted their teaching, they wanted to use the teaching methods which their teachers had used as this was their only experience with teaching in the university classroom. Hegelsen (1988) and Hansen \& stansfield (1982) claim that teachers usually teaches in the style they had been taught. However, the chinese teaching methods do not fit the U.S. classroom in part because they do not serve the U.S. educational values.

As discussed in Chapter II, Schutz's (1967) position is that the world is organized by rules of typicality and 
people behave and interpret the meaning they will experience by following these rules. These rules, called formulas or social recipes, are typical, well-understood ways of doing things. Chinese TAs' formulas for university classroom communication were initially learned in the culture of the Chinese classroom, formulas which guided CTAs' expectations and interpretations of their own behaviors and others' behaviors. However, the context of the U.S. classroom is organized drawing on a different set of rules, thus, the formulas CTAs brought with them from the Chinese classroom context do not serve to guide their behavior in the U.S. university classroom, nor help them adequately and accurately interpret the behaviors of others. The CTAs interpreted such student behaviors as sitting in the classroom comfortably, eating and drinking in the class, not showing up, asking questions, interrupting and arguing with the teacher as uncooperative or disrespectful of the teacher. Although typical in many U.S. university classrooms, these behaviors were labelled as rude, suggesting that CTAs found it difficult to cope with behaviors reflective of U.S. values which emphasizes "individualism", "competitiveness" and "aggressiveness" (Costantino, 1987, p. 291).

Thus, here the rules of typicality do not hold. Formulas which worked quite well in the chinese university classroom do not fit the U.S. university classroom setting. 
This lack of a good fit affects CTAs' communication in the U.S. university classroom. In order to communicate effectively in the U.S. university classroom, CTAs have to reconstruct their formulas of classroom communication and have to learn the underlying rules upon which formulas are based and constructed.

Thus, along with other studies of ITAs (Constantinides \& Byrd, 1986; Costantino, 1987; Sadow \& Maxwell, 1982; Bernhardt, 1977; Pica, Barnes \& Finger, 1990; Shaw \& Garate, 1984; Ronkowski, 1987; Saal, 1987; Byrd, Constantinides \& Pennington, 1989), the Chinese TAs' experiences in this study reveal that one of the factors which reduces CTAs' ability to communicate effectively in the U.S. classroom is their undergraduate educational background experienced in their own culture. More specifically, this study suggests that CTAS' expectations of the U.S. professor's and students' behaviors are influenced by their educational experiences in China, experiences which reflect a different system of values and that this affects current classroom interactions.

Cultural Expectations of Students' Mathematical Capabilities

In the Chinese educational system, mathematical ability is highly valued and considered as a foundation of the higher education. All students take mathematics courses for six years in high school and take a mathematics examination before they enter universities, whether they major in 
natural sciences, engineering, social sciences, or humanities. Only the students who pass with a certain score on the examination can be admitted to universities. Thus, all Chinese university students are assumed to have achieved the same mathematical level. Mathematical ability is considered an indicator of overall academic capabilities of college students and as "a shared language of classroom communication" ( $M$; 3 years; 2 years). Such a situation makes teaching and learning easier.

Among the seventeen CTAs interviewed in this study, fourteen ( 828 ) were TAs in natural sciences and engineering departments. The interview data revealed that the CTAs expected U.S. students to have achieved the same mathematical level as they had in their home country. Unfortunately, they found that their expectations and U.S. students' actual mathematical abilities did not match.

The U.S. educational system has different requirements of mathematical ability. Public high schools in oregon only require two years of math although high school college preparatory programs encourage students to take additional mathematics courses. Moreover, public colleges and universities with an "open-door" policy (Deegan \& Tillery, 1985; see Chapter II, Pp. 15-16) admit students regardless of their mathematical level. Therefore, it is likely that students' math abilities will vary greatly. Faced with this classroom non-matching, CTAs felt frustrated whenever 
they explained math-related problems to students. Chinese TAs attributed this communication impasse to a lack of shared mathematical background between CTAs and U.S. students, not to their own ability to communicate in English with students. They believe this situation contributes to communication difficulties between themselves and their students. This view is well summarized in the following quote:

Communication between students and TAs should
be considered from two sides. When I came to
the U.S. first term was really difficult for
me. Even though I studied English in China,
I still had language problem, especially
listening. This is one side. The other side
is that most American students are very weak
in math. Their questions are related not only
to physics subject, but math as well. when you
answer their questions, they feel difficult in
understanding physical knowledge, and math as
well. so most time, when I answer their
questions, I have to explain to them not only
physics but math as well. ... Such a low level
of math can't help them understand physics
problems. When I explained the problems to
them, they couldn't follow. When they
couldn't follow, or understand the explanations,
they complained about my language, rather than
their low math level. ... Indeed, there is
language problem, this is one side; the other
side is the American students are too weak in
math to take college physics. (F; 5 years;
5 years)

Chinese TAS' experience revealed that their cultural expectations influenced their perceptions of U.S. students and their attributions of the students' mathematical capabilities. They found that the students were weak in mathematics, lacked basic knowledge of natural sciences and 
were at different academic levels. Such descriptions of U.S. students' mathematical level do not appear in CTAs' descriptions of Chinese students, because CTAs never experienced the phenomenon of asking questions about such math problems as $x: 55=80: 100$ or $3 / 4+4 / 5$ in the context of the chinese university classroom and they did not have these categories in their culturally structured expectations. Thus, the students' dissimilar mathematical capabilities became salient for CTAS' perceptions of U.S. students. As Ehrenhaus (1983) notes:

Different features of the interaction are seen by culturally disparate attributors as salient, and these differing salient features cue each attributor to rely upon his or her familiar structures of expectations. (p. 164)

In the perception process, similarities between U.S. and chinese students became secondary and dissimilarities caught the CTAS' main attention and strong judgements (Detweiler, 1978). These perceived dissimilarities became the source of negative interpretations. Brislin (1981) asserts that individuals are likely to be influenced by the negativity effect given perceived cultural dissimilarity and that negative information about dissimilarity is considerably more influential than positive information. Based on their perceptions of U.S. students' mathematical capability, CTAs drew negative conclusions about U.S. students, describing them as very weak in math, much weaker 
in basic knowledge than they should be, and suggesting that some of them could not be called college students. In addition, CTAs attributed this dissimilarity in math ability to person-related rather than context-related factors, that is, U.S. students had lower math abilities because they do not care about their studies, do not spend enough time on their studies and do not think math is important.

The difference between CTAs' expectations and students' mathematical level also made CTAs feel that teaching is difficult. They found that it was not easy to teach students of varying math levels in the same class because they had to be prepared to answer a variety of questions of different levels - from high school algebra and geometry to college calculus and statistics - and in different subjects - from mathematics to chemistry and physics. Such conditions made CTAs doubt the quality of U.S. postsecondary education. A respondent commented:

Some of American students are good, but some of them are lower than Chinese students academically. Because in China all college students have to pass the entrance exam, so the students are almost in the same academic level. However, here [U.S.] rank is quite big. Such a situation gives me an impression that American education is not as good as that in China. (M; 6 years; 5 years)

The intensity of the CTAs' evaluation is likely compounded by the fact that math ability is both highly valued in Chinese culture and is considered an indicator of 
overall academic ability. Thus, attributions of students' overall academic capability appears to be based on one set of skills as is the CTAs' evaluation of higher education in the U.S.

However, even among U.S. educators the low math level of U.S. students is a big concern. According to the U.S. Educational Department, mathematics is "a subject in which American students rank way below their counterparts in most industrialized countries." "Only one in five eighth graders has achieved competence for his or her age level" (Newsweek, October, 14, 1991, p. 54). Very recently, the National Assessment of Educational Progress (NAEP) reported a national survey of math-achievement level of high-school seniors: "More than a third of 12th graders could not master grade-level basics; only a few (2.6\%) could do advanced work" (Newsweek, October 14, 1991, p.54).

Thus, although CTAs' own cultural background, that is values, beliefs as well actual experiences, influences their perceptions and negative evaluations of U.S. students, their view of students in this university being weak in math is a view shared on a broader scale among other U.S. educators. The Chinese TAs do not seem to be misperceiving the situation. The U.S. students' math ability is recognized even among U.S. educators as being low. Their examples of students' math difficulties such as x:55=80:100, and $3 / 4+$ $4 / 5=$ ? could be useful information not only for other ITAs 
to understand students' math levels, but also for universities and $\mathrm{K}-12$ educators as they consider the current problems with math education, both in this state and elsewhere.

The mathematical capability of U.S. students was a critical topic in the interviews. The natural sciences and engineering CTAs considered it as a factor which could affect classroom communication between CTAs and their students, however, social sciences and humanity CTAs (18\%) did not have such a experience.

\section{CTAS' ADAPTATION TO THE U.S. UNIVERSITY CLASSROOM}

Chinese teaching assistants (CTA), like any foreign students coming to study at a U.S. university, must undergo a process of acculturation in order to be effective in the U.S. university classroom, a particular situation in the U.S. culture. As discussed in Chapter II, Detweiler, Brislin and Mccormack (1983) suggested that situations predict behavior and an adequate understanding of how situations vary has tremendous promise for improving intercultural adjustment. Interview data revealed that CTAs employed specific strategies to adapt to behavioral and communication patterns of the U.S. university classroom, however, they were not quite aware of cultural values behind the behavioral and communication patterns. 
CTAS' Adaptation Strategies

Chinese TAS' adaptation to the U.S. university classroom includes three specific strategies: imitating, preparing and adopting. First, they imitated the U.S. professor's behavior, for example, sitting on the desk and joking with students, by watching, taking courses and working with other TAs. The following quotes reflect this adjustment process.

... from the second term, I felt more and more relaxed. ...I consciously or unconsciously learned a lot from them [U.S. professors]. They sit on the desk, I can do the same thing. ...I changed a lot and tried to be informal. I made jokes and smiled, talked about their wives and daughters. ( $M$; 1.5 years; 3 terms)

Second, CTAs prepared in specific ways for being an instructor. Before actually assuming teaching responsibilities, CTAs work with other experienced TAs, tutored students, and performed laboratory experiments by themselves. Such preparation helped CTAs obtain information about the U.S. higher education system, the classroom setting, U.S. students, and course content which they were going to present to students.

Finally, CTAs tried to adopt U.S. teaching styles in their classroom teaching. Some of them changed from formal to informal, serious to casual, and focused to loose teaching styles; other CTAs combined Chinese and U.S. teaching styles because they believed that each had some 
strengths and weakness. No matter what teaching style they adopted in their classroom, all of them held positive attitudes toward students' behavior of asking questions. A Chinese TA commented: "No questions, no communication." (F; 2 year; 1 year). The following quotes reflect their teaching style.

When I teach, I like my students to learn everything in a relaxed way. So when I begin my class, I like to make a joke and make them relax and feel that they can spend an hour comfortably in this class. ( $M$; 1 year; 3 terms)

I encouraged my students to ask questions in the class. ... If students are quiet, I don't know if they understand or not. Do I need to repeat? slow down? speed up? or stop? I like to see their responses. (F; 2 years; 1 year)

\section{Two Levels of Adjustment}

Bennett (1986) described two major levels of adjustment in the acculturation process:

First is the acceptance of behavioral

difference, including language, communication

style, and nonverbal patterns. Second is acceptance of the underlying cultural value differences which may represent profoundly different organizations of reality. (p. 184)

The Chinese TAs in this study seemed to experience these two levels of adjustments in adapting to the U.S. classroom setting. Their strategies of imitation, preparation and adoption help them learn how to behave and communicate appropriately in the U.S. university classroom, that is, to learn formulas or rules of the U.S. university 
classroom behavior and communication, which, according to Bennett (1986), is the first level of adjustment in the acculturation. The second level of adjustment is a metalevel of adjustment to the classroom setting. It requires CTAs to be aware of why U.S. students and professors behave and communicate in particular ways and what they value in the classroom setting, in other words, CTAs need to learn the underlying cultural values and rules for enactment of classroom behavior. As a CTA put it:

\begin{abstract}
...to know cultural differences between America and China, then you can understand why American students do this in that way. A big difference between chinese students and American students is [that] Chinese students are quiet and they listen to you. They show their respect to you. But here [in the U.S.], they [U.S. students] grow up with equality, so they can argue with you and sometimes anything can happen. ( $F ; 1.5$ years; 4 terms)
\end{abstract}

Unfortunately, not all the CTAs who participated in this study seemed to have a clear recognition of U.S. cultural values in general and the U.S. educational values in particular. Chinese TAs paid attention to adjusting to visible classroom behavior; however, few of them were aware of and talked about underlying American cultural values and their relationship to actual classroom communication behavior. Interview data suggested that length of stay in the U.S. was a factor and that the longer CTAs were here, the more aware they were of the U.S. cultural values. 


\section{IMPLICATIONS FOR ITA TRAINING PROGRAMS}

\section{Training Program Type}

Chinese TAs participating in this study agreed that training would help them. Most of the Chinese students were employed to be TAs after they came to the U.S. They realized the importance of becoming familiar with the U.S. university before starting their teaching and suggested that both pre-term and concurrent-term ITA training programs be offered. AlI seventeen respondents described the difficulties they encountered in their first term of teaching. For example:

[In] the first term, the most difficult is language. Because we learned English in China. It is British English and additionally each person has his own accent. (M; 1 year; 3 terms)

I think it's difficult in the first term. At the beginning, when students asked me questions, I sometimes didn't understand them. (M; 6 years, 5 years)

When I was a TA in the first term, I was nervous. Gradually I felt better and better. It's hard to tell how long it takes to get a comfortable feeling. ( $M$; 4 years; 7 terms)

I didn't feel confident when I taught in the first term. I didn't have teaching experience before. ( $\mathrm{F} ; 1.5$ years; 4 terms)

The first term is really difficult because I am not familiar with American students. (F; 1 year; 1 term)

When I was a TA in the first term, it was very hard. The experiments here are little bit different from those in China. I had to do all 
the experiments myself in order to be familiar with lab work. ( $M$; 4 years; 4 years)

The foregoing comments reflect some of the CTAs' needs that might be well be addressed before they begin to teach. Portland State University (PSU) does not provide a general pre-term training program, although some departments have their own pre-term training programs. Chinese TAs commented that these pre-term programs gave CTAs ideas about the university and their departments, and helped them gain confidence teaching in the U.S. classroom.

Based on CTAS' comments in the interviews about the ITA training programs, a pre-term program is helpful but not enough. A concurrent-term program can help CTAs adjust to U.S. university classroom linguistically, pedagogically and culturally because it is held while CTAs are teaching and they can bring their fresh questions to the meetings and discussions or share their experiences with other ITAs. Portland state University, through the Center of English as a Second Language (the ESL Center), offers some courses for PSU'S ITAS. Some CTAS commented that these courses were helpful, especially discussions and case studies facilitated CTAS' familiarity with and adjustment to the U.S. classroom; however, they found that a term-long course was not adequate to improve their classroom communication and suggested that a long term training program would be more helpful. 
Training Program Content

The Chinese TAS' experiences suggested that they needed help in practicing American English, knowing how to be a U.S. teacher and understanding U.S. university classroom culture. Thus, the program content covering these three topics would meet the CTAS' needs and strengthen the training programs in Portland state University. The following reflects their suggestions.

Being a foreign TA, I think it's important to speak good English. The second important thing is to know the topics you're going to teach.

Also you have to prepare well before conducting a class. (M; 4 years; 7 terms)

...make sure that their [CTA] English understandable. ...TOEFL can tell your English in some way, but not how well you speak English. (M; 4 years, 4 years)

I think it's important to know general rules about teaching, how to communicate with students, how to help them, especially in math, and how to conduct a class. ( $F$; 2 years; 1 year)

Foreign TAs should be shown the American educational system. ( $F$; 5 years; 5 years)

In terms of language the CTAs felt that they already knew English phonological rules, synthetic rules and some semantic rules. What they needed was to improve their listening and speaking abilities and to acquire American English. From their perspective, one of the best ways to achieve this goal was to teach in real classroom settings, and the training program could help them prepare for their 
teaching. Most ITA training programs mentioned in the literature (Abraham \& Plakans, 1988; Chase, 1970; Bailey, Pialorsi \& Faust, 1984; Chism \& Warner, 1987; David, 1987; Sarkisian, 1985; Sequeira \& Costantino, 1989; and StatonSpicer \& Nyquist, 1979), including training courses offered by the ESL Center of PSU, emphasize basic language skills training due to students' complaints about ITAs' English proficiency. However, CTAs participating in this study suggested that training in English linguistic rules did not help very much with their language proficiency since all of them had learned these rules in China (see p. 57). Rather, they wanted information about American English expressions and practice in public speaking skills.

Knowing how to be a U.S. teacher is another important topic of the training program. CTAs' experiences showed that they needed to be told about general rules of being a U.S. teacher, especially in their first term of teaching, such as how to conduct classroom and laboratory teaching, how to prepare course syllabi, tests, how to give grades, and to be on time for the class and to keep office hours. Samples of course syllabi and test papers would be helpful. The pre-term training programs of departments at PSU provided such information for CTAs.

Besides knowing how to be a U.S. teacher, CTAs also need to get general information about U.S. students, especially their academic levels of mathematics and natural 
science. With this information, CTAs would be better able to cope with students' varying math levels and be able to prepare their teaching plans to fit students' mathematical ability. Unfortunately, neither PSU's departments' training programs nor the ESL Center's courses provided such information for CTAs so that they were shocked by students' math ability in their classroom interactions with students. This study suggests that offering information about U.S. students' academic levels in the training programs would greatly help CTAS understand the U.S. undergraduate students, reducing their negative attributions and increasing their adaptation to potential frustrating classroom situations.

The third topic suggested by CTAs participating in this study is an understanding of the U.S. educational system and the classroom culture. The United States has a different educational system from China, therefore, it is important for CTAs to perceive the differences and understand values of the U.S. education. For example, if CTAs can understand that open access to public colleges and universities is one of the features of the U.S. higher education which provides students with more opportunities to receive higher education in spite of their academic backgrounds, they would begin to realize why U.S. students have varying mathematical levels. This information may help them not shocked by students' 
"silly" questions and may alter their negative attributions of U.S. students.

Equally important is to know about the U.S. classroom culture. Rather than a focus on information memorization, theory-oriented learning, cooperation and collective goals, U.S. classroom instruction emphasizes educating for creative thinking, use of problem-solving techniques, competition and individual goals. If CTAs are not clear about this emphasis, it is difficult for them to understand why asking questions is encouraged, why students are offered a chance to enroll in any courses they are interested in, and why classroom discussions and course projects are more highly valued than memorizing information.

This topic has not been received much attention in ITA studies and most training programs including programs in PSU focus on language skilis rather than U.S. university classroom culture (Sequeria \& Costantino, 1990; Constantinides, 1987B; and Saal, 1987). This study highly recommends that not only is it important for CTAs to learn English, but they must also be aware of U.S. classroom culture and adapt to it in order to more effectively teach in the U.S. classroom.

\section{IIMITATIONS OF THE STUDY}

The study was designed to collect data by both in-depth face-to-face interviews and classroom observations. 
However, only one interview was conducted with each CTA. A second interview would have been very helpful to follow up on statements that were not fully elaborated during the first meeting.

Data from direct observations were of limited value for this study for a number of reasons. First, coming from the same culture as the study participants, I was so familiar with CTAs' classroom behavior that this shared background may have blinded me to the significance of CTAs' behavior, particular nonverbal behaviors. Second, I, as an investigator, had limited training in observational techniques. Also, the categories of the observation guide were useful, but too extensive for a single observation. Therefore, the descriptions and interpretations of the CTAs' classroom communication experiences are primarily based on the interview data.

In addition, this study was limited by sample size and the population it represents: it only included CTAs teaching at one U.S. university. Thus findings about CTAs are not generalizable beyond this study.

Finally, the issue of intercultural communication between ITAs and U.S. students involves both sides and each side perceives the issue differently. This study focuses on CTAs' perceptions from their own perspective. The other side, the U.S. students' perceptions, was not included in this study. 
Although this study has some limitations, it has met its purposes and the results have answered the inquiry of the study: What are CTAs' communication experiences in the U.S. university classroom from their perspective? How do they interpret their own experiences? How do they adapt to the U.S. classroom setting? The research design fit the purposes of the study and valuable and rich data have been collected through in-depth interviews. Based on the CTAs' descriptions of their own experiences, the study explored CTAs' reality of classroom communication and their perceptions of "foreign TA problem" and interpreted that CTAS' classroom communication was influenced by their cultural background. Finally, the study offers suggestions for ITA training programs, including program types and content that could strengthen existing programs both at PSU and other universities.

\section{FUTURE RESEARCH}

As discussed early in this chapter, students' mathematical ability was perceived by most CTAs as a big issue of classroom communication. Thus, it is highly recommended that a similar study be conducted in other U.S. universities. For example, some of these universities could be similar to Portland State University (PSU) where students have varying levels of mathematical abilities, while others could be different universities that require particular 
levels of mathematical ability on entrance. Findings from each could be compared to see whether students' mathematical ability is still considered as a factor affecting classroom communication among Chinese TAs in the two different settings.

Chinese TAs' logic process, that is, the way in which they organize course content, needs further study. The literature (Reid, 1987; Constantinides \& Byrd, 1986) suggests that the difficulty in learning/teaching in the classroom; high frustration levels and even failure may not rest solely in teachers' "poor English", but rather, may be related to a teaching methods that reflects the teacher's rather than students' cultural logical system. Because Chinese dominant logic pattern is different from that in the U.S. culture, the difference of two logic systems might cause breakdown in classroom communication. Insufficient data were available in this study to ascertain whether different patterns of logic exist between CTAs and their U.S. students, and if so, to what extent this influences the ways CTAs present information and finally its effect, if any, on classroom communication. Further study of the possible existence of culturally determined patterns of logic and their relative impact on classroom teaching would be useful.

An additional area of research which needs further exploration is CTAS' adaptive process to the U.S. university 
classroom. What factors facilitate or affect the adaptation? For instance is gender a factor, or length of stay in the U.S., or length of time being a TA.

Findings in this study are based on interview data with seventeen CTAs. It is ideal to explore CTAS' experiences of classroom communication both verbally and nonverbally. China is a high-context culture where "simple messages with deep meaning flow freely" and "meaning ... is embedded in the physical context" (Hall, p. 91), therefore, a study of CTAs' nonverbal behavior would provide an additional important information about CTAs' classroom communication.

\section{CONCLUSION}

Using a phenomenological perspective, this study explored Chinese TAS' communication experience in a U.S. university classroom from their point of view. The collected data in this study reveals that CTAs' classroom behavior and communication are influenced by their cultural background and that their expectations of a university classroom setting and U.S. students' academic level do not fit the U.S. higher education which, in turn, affects their classroom communication with students. The CTAs' experiences in the U.S. university classroom suggest that ITA training programs need to focus on enhancing ITAs' communication competence which includes language proficiency and understanding of the U.S. classroom culture in order to 
help ITAs more effectively teach in the U.S. university classroom. 
REFERENCES

Abraham, R.G. \& Plakans, B.S. (1988). Evaluating a screening/training program for NNS teaching assistants. TESOL Quarterly, 22, 505-508.

Alexander, A., Cronen, V., Kang, K. , Tsou, B. \& Banks, B.J. (1986). Patterns of topic sequencing and information gain: A comparative study of relationship development in Chinese \& American cultures. Communication Quarterly, 34 (1), 66-78.

Anderson-Hsieh, J. (1990). Teaching suprasegmentals to international teaching assistants using field-specific materials. English for Specific Purposes, 9, 195-214.

Bailey, K.M., Pialorsi, F., \& Zukowski/Faust, J. (Eds.) (1984). Foreign teaching assistants in U.S. universities. Washington, D.C.: National Association for Foreign Student Affairs.

Bennett, M.J. (1986). A developmental approach to training for intercultural sensitivity. International Journal of Intercultural Relations, 10, 179-196.

Bernhardt, E. (1977). Training foreign teaching assistants: Cultural differences. College Teaching, 35, 67-69.

Brislin, R. (1981). Cross-cultural encounters. New York: Pergamon Press.

Buerkel-Rothfuss, N.L. \& Gray, P.L. (1990). Graduate teaching assistant training in speech communication and noncommunication departments: A national survey. Communication Education, 39, 292-307.

Bulmer, M. (1979). Concepts in the analysis of qualitative data. Sociological Review, 27, 651-677.

Byrd, P., Constantinides, J.C., \& Pennington, M.C. (1989). The foreign teaching assistant's manual. New York: Macmillan.

Byrd, P., \& Constantinides, J.C. (1988). FTA training programs: Searching for appropriate teaching styles. English for Specific Purposes, I, 123-129. 
Chase, J.L. (1970). Graduate teaching assistants in American universities: A review of recent trends and recommendations. Washington, D.C.: U.S. Department of Health, Education and Welfare, Office of Education.

Chism, N., \& Warner, S.B. (Eds.) (1987). Employment and education of teaching assistants. Columbus, $\mathrm{OH}$ : The Ohio State University, Center for Teaching Excellence.

Constantinides, J. \& Byrd, P. (1986). Foreign TA's: What's the big problem? Journal of International student Personnel, $3,27-32$.

Constantinides, J.C. (1987a, March). The "foreign TA problem" -- an update. NAFSA Newsletter, 38, 3-6.

Constantinides, J.C. (1987b). Designing a training program for international teaching assistants. In N. Chism \& S. Warner (Eds.), Employment and education of teaching assistants (pp. 275-283). Columbus, $\mathrm{OH}$ : The Ohio state University, Center for Teaching Excellence.

Constantinides, J.C. (1989). ITA training programs. In J.D. Nyquist el (Eds.) Teaching assistant training in the 1990s (pp.71-78). San Francisco, CA: Jossey-Bass, Inc.

Costantino, M. (1985). Training international teaching assistants: Policy and procedures. Journal of International student personnel, $2,1-5$.

Costantino, M. (1987). International communication for international teaching assistants: observations on theory, pedagogy, and research. In N. Chism \& S. Warner (Eds.), Employment and education of teaching assistants (pp. 290-300). Columbus, OH: The Ohio State University, Center for Teaching Excellence.

David, B. (1987). The effectiveness of videotaped protocols as a training technique for international TAs. In $\mathrm{N}$. Chism \& S. Warner (Eds.), Employment and education of teaching assistants (pp. 321-333). Columbus, $\mathrm{OH}$ : The ohio state University, Center for Teaching Excellence.

Deegan, \& Tillery, (1985). Renewing American community colleges. San Francisco, CA: Jossey-Bass Publishers.

Detweiler, R. (1978). Culture, category width, and attributions: A model-building approach to the reasons for cultural effects. Journal of Cross-Cultural Psychology, 9, 259-284. 
Detweiler, R., Brislin, R. \& McCormack, W. (1983).

Situational analysis. In D. Landis \& R. Brislin (Eds.),

Handbook of International Training (pp. 100-123). New

York: Pergamon Press.

Diamond, R.D. \& \& Gray, P. (1987). National study on

teaching assistants. New York: Syracuse University,

The Center for Instructional Development.

Duncan, B. (1976). Differential social penetration and attribution of intergroup violence: Testing and lower limits of stereotyping of blacks. Journal of Personality and social Psychology, 34, 590-598.

Dunkel, P.A., \& Rahman, T. (1987). Developing listening and speech communication skills: A course for prospective international teaching assistants. In N. Chism \& S. Warner (Eds.), Employment and education of teaching assistants (pp. 301-306). Columbus, OH: The Ohio State University, Center for Teaching Excellence.

Eck, J.S. (1987). Screening international TAs for oral English proficiency. In N. Chism \& S. Warner (Eds.), Employment and education of teaching assistants (pp. 348-350). Columbus, OH: The Ohio State University, center for Teaching Excellence.

Ehrenhaus, P. (1983). Culture and the attribution theory. In W. Gudykunst (Ed.), Intercultural Communication Theories, (pp.259-270). Beverly Hills, CA: Sage Publications.

Gillespie, J. K. (1988). Foreign and U.S. teaching assistants: An analysis of verbal and nonverbal classroom interaction. Unpublished doctoral dissertation, University of Illinois at UrbanaChampaign, Champaign, Illinois.

Goetz, J.P. \& LeCompte, M.D. (1980) . Ethnographic research and the problem of data reduction. Anthropology and Education Quarterly, 12, 51-70.

Gorman, R. (1977). The Dual vision: Alfred Schutz and the myth of phenomenological social science. London: Routledge \& Kegan Paul.

Gudykunst, W.B. (1983). Uncertainty reduction and predictability of behavior in low and high-context cultures: An exploratory study. Communication Quarterly, 31 (1), 49-55. 
Hansen, J. \& Stansfield, C. (1982). Student-teacher cognitive styles and foreign language achievement. Morden Language Journa1, 66, 263-273.

Hegelsen, M. (1988). Natural style and learning style preferences: Their effect on teaching and learning. University of Illinois and Urbana-Champaign: Instruction and Management Services.

Hinofotis, F. \& Bailey, K.M. (1980). American undergraduates' reactions to the communication skills of foreign teaching assistants. On TESOL'80 (pp. 120133). Washington, D.C.: TESOL.

Hus, F.L. (1981). Americans \& Chinese: Passage to differences. Honolulu, HI: The University Press of Hawaii.

Husserl, E. (1962). Ideas: General introduction to pure phenomenology. New Yrok: Collier Books.

Jordan, C. (1982). Cultural differences in communication patterns: classroom adaptations \& translation

strategies. On TESOL'82 (pp. 285-294). Washington, D.C.: TESOL.

Kaplan, R.B. (1980) . Cultural thought patterns in intercultural education. In K. Croft (Ed.), Readings on English as a second language (2nd ed.), (pp. 390-418). Boston, MA: Little, Brown \& Company.

Kelley, H. (1972). Attribution in social interaction. In E. Johns, D. Kanouse, H. Kelley, R. Nisbett, S. Valins, \& B. Weiner (Eds.), Attribution: Perceiving the cases of behavior (pp.1-26). Morristown, NJ: General Learning Press.

Kim, Y.Y. (1988). Communication and cross-cultural adaptation: An integrative theory. Clevedon, $\mathrm{PH}$ : Multilingual Matters Ltd.

Lalande, J., \& Strasser, G. (1987). A survey of international teaching assistants in foreign language department. In N. Chism \& S. Warner (Eds.), Employment and education of teaching assistants (pp. 251-262). Columbus, OH: The Ohio state University, center for Teaching Excellence.

Littlejohn, S.W. (1989). Theories of human communication. Belmont, CA: Wadsworth Publishing Company. 
Lofland, J. \& Lofland, L. (1984). Analyzing social settings: A guide to qualitative observation \& analysis. Belmont, CA: Wadsworth Publishing Company.

Lowman, J. (1984). Mastering the techniques of teaching. San Francisco: Jossey-Bass.

Mccraken, G. (1988). The long interview. Newbury Park, CA: Sage Publications.

Mellor, J. (1987). Standard oral proficiency tests for international graduate teaching assistants. In $\mathrm{N}$. Chism \& S. Warner (Eds.), Employment and education of teaching assistants (pp. 334-347). Columbus, OH: The ohio state University, Center for Teaching Excellence.

Nyquist, J.D., Abbott, R.D. \& Wulff, D.H. (1989). Teaching assistant training in the 1990s. San Francisco, CA: Jossey-Bass Inc.

Open Doors. (1990). New York: Institution of International Education.

Patton, M.Q. (1990). Qualitative evaluation and research methods. Newbury park, CA: Sage Publications.

Philipsen, G. (1984). The qualitative case study as a strategy in communication inquiry. The communicators, 12, 4-17.

Pia, A. (1989). Preferred perceptual learning styles of Chinese students. Unpublished master thesis, Portland State University, Portland, Oregon.

Pica, T., Barnes, G.A. \& Finger, A.G. (1990). Teaching matters: skills and strategies for international teaching assistants. Philadelphia, : Newbury House Publishers.

Pilotta, J.J. (1983). The phenomenological approach, in $\mathrm{W}$. Gudykunst (Ed.), Intercultural Communication Theories, (pp. 271-282). Beverly Hills, CA: Sage Publications.

Reid, J. M. (1987). The learning style preferences of ESL students. TESOL Quarterly, 21, 87-111.

Ronkowski, S. (1987). International and American TAs: Similarities and differences. In N. Chism \& S. Warner (Eds.), Employment and education of teaching assistants (pp. 263-266). Columbus, OH: The Ohio state University, Center for Teaching Excellence. 
Rounds, P.L. (1987). Characterizing successful classroom discourse for NNS teaching assistant training. TESOL Quarterly, 21, 643-671.

Saal, D.R. (1987). The undergraduates experience and international teaching assistants. In N. Chism \& $S$. Warner (Eds.), Employment and education of teaching assistants (pp. 267-274). Columbus, $\mathrm{OH}$ : The Ohio State University, Center for Teaching Excellence.

Sadow, S.A. \& Maxwell, M.A. (1982). The foreign teaching assistant and the culture of the American university class. On TASSEL'82 (pp. 253-258). Washington, D.C.: Teachers of English to Speakers of Other Languages.

Sarkisian, E. (1985). Training foreign teaching assistants: Using videotape to observe and practice communicating and interacting with students. on TESOL'84 (pp. 325331). Washington, D.C.: Teachers of English to Speakers of Other Languages.

Schutz, A. (1967). The Phenomenology of the social world. Evanston, III: Northwestern University Press.

Schutz, A. (1970). On Phenomenology and social relations. Chicago, IL: The University of Chicago Press.

Sequeira, D. \& Costantino, M. (1990). Issues in ITA training programs. In J.D. Nyquist el (Ed), Teaching assistant training in the 1990s (pp. 79-86). San Francisco, CA: Jossey-Bass, Inc.

Sequeira, D., \& Darling, A. (1987). A multiperspective approach to international teaching assistant training: The international teaching assistant project of the center for instructional development and research, University of Washington. In N. Chism \& S. Warner (Eds.), Employment and education of teaching assistants (pp. 307-315). Columbus, OH: The Ohio state University, Center for Teaching Excellence.

Shaw, P.A., \& Garate, E.M. (1984). Linguistic competence, communicative needs, and university pedagogy: Toward a framework for $T A$ training. In $K$. Bailey, F. Pialorsi \& J. Zukowski/Faust (Eds.), Foreign teaching assistant in U.S. universities (pp. 22-40) . Washington, D.C.: National Association for Foreign Student Affairs. 
Smith, R. (1987) . Training international TAs at Texas Tech: An overview. In $\mathrm{N}$. Chism \& $\mathrm{S}$. Warner (Eds.), Employment and education of teaching assistants (pp. 318-320). Columbus, $\mathrm{OH}$ : The Ohio State University, Center for Teaching Excellence.

Staton-Spicer, A.Q. \& Nyquist, J.L. (1979). Improving the teaching effectiveness of graduate teaching assistants. Communication Education, 28, 199-205.

Stewart, E.C. (1972). American cultural patterns: A crosscultural perspective. Pittsburgh, PE: Regional Council for International Education.

Taylor, S.J. \& Bogdan, R. (1984). Introduction to qualitative research methods: The research for meanings. New York: John Wiley \& Sons.

Yule, G. \& Hoffman, P. (1990). Predicting success for international teaching assistants in a U.S. University. TESOL Quarterly, 24, 227-243. 
APPENDIX A

INFORMED CONSENT

I,

hereby agree to serve as a respondent in the research project entitled "A qualitative case study of Chinese teaching assistants' communication in the U.S. university classroom" conducted by Lina Lu under the supervision of Susan Poulsen, Ph.D.

I understand that the study involves verbally responding to questions asked by Lina $\mathrm{Lu}$ and classroom observation conducted by Lina Lu.

It has been explained to me that the purpose of the study is to learn how chinese teaching assistants experience their interaction with U.S. students in the classroom at Portland State University.

I may not receive any direct benefit from participation in this study, but my participation may help to increase knowledge which may benefit others in the future.

Lina Lu has offered to answer any questions I may have about the study and what is expected of me in the study. I have been assured that all information I give will be kept confidential and that my identity will be protected in any discussion of result or in any written research summary.

I understand that I am free to withdraw from participation in this study at any time without jeopardizing my relationship with Lina Iu, persons who may have referred me to this study, Portland State University, or the college or university I am attending.

I have read and understand the foregoing information.

Date

Signature

If you experience problem that are the result of your participation in this study, please contact secretary of the Human Subjects Research Review Committee, Office of Grants and Contracts, 345 Cramer Hall, Portland State University, (503) $725-3417$. 
APPENDIX B

CHINESE TEACHING ASSISTANT

DEMOGRAPHIC INFORMATION

1. Department

2. Class being taught

3. Sex

4. Years/months in the U.S.

5. Degree gained

In which country

6. Degree sought in U.S.

7. How many terms as TA

8. How many terms teaching this course

9. Did you teach in your home country? Yes No

How many years

What did you teach

10. How long have you studied English

In your home country

In the U.S.

11. TOFEL score (optional)

Respondent Number 
APPENDIX C

\section{OBSERVATION GUIDE}

Course observed

Dept.

Type of class (lecture, lab, discussion,etc.)

Content being taught

Date Time Time of the term

1. What was Chinese teaching assistant (CTA) wearing ?

2. What did CTA do from the time he/she entered the room until the class began?

3. How did CTA signal the class would begin?

4. Language activities

a) speaking:

1) to entire class

2) to individual student (when, why, how many times)

b) reading:

3) to self (when, why, how many times)

c) writing:

1) from textbook/newspaper/overhead projector

1) on chalkboard/overhead transparency

2) was the writing easy to read

d) listening:

1) to student questions

2) to students answer to ITA's questions

5. Nonverbal acts

a) movement: 1) walking around/ to chalkboard/ back to look at what is written on the board

2) standing behind desk (how long)

3) sitting down (where)

4) moving away from the front-and-center

b) gestures: 1) pointing (at what? at whom? which finger?)

2) making a fist/a stop gesture with palm

3) gesture to indicate growth or expansion/shrinking or loss

4) taking glasses off/putting glasses on

5) touching own body/student (where? what seems to be meant?)

6) other hand gestures (meaning)

7) raising eyebrows

8) other facial gestures

c) eye-contact 1) looking at (where) and direction (left, right, straight)

2) numbers of looking at each student

d) other physical actions

6. Paralinguistics: pronunciation/pitch/volume/tone/rate/fluency

7. How did CTA signal that the class was finished ?

8. What did CTA do from the time the class finished until he/she left the room ? 


\section{APPENDIX D}

\section{INTERVIEW GUIDE}

1. Thanks for agreeing to participate in my study. What do you think of your class which I observed? How was it having me sitting in your class?

2. Tell me some of your interesting experiences teaching at Portland State University that you never experienced in China.

3. Are there any differences in your teaching between the first term you taught and this term? If not, why? If yes, what are they?

4. Do you have any difficulties when you communicate with your students in the classroom? If not, why not? If yes, what do you think contributes to the difficulties?

5. How do you handle these difficulties? How successful do you feel you are handling these difficulties?

6. What your students' classroom behaviors surprise you?

7. What do you think of students' asking questions and interrupting in the classroom? How do you respond?

8. Would you describe to me of your teaching method? Do you teach here in the same way as you did in China? If not, in which aspect do you change your way? Why?

9. What kind of teacher-student relationship do you create? Do you feel comfortable with it?

10. What aspect of speaking do you feel is the most difficult for you when you teach? How do they affect your communication in the classroom?

11. What do you wish you had known when you first started teaching at PSU ?

12. What do you think of a TA at PSU? Do you enjoy it? Do you think it helps you academically or socially?

13. In thinking about teaching here and what we have been talking about, is there anything else you would like to say? 